\title{
Sociología de la vejez versus economía de la vejez
}

\author{
Pedro Sánchez Vera \\ Universidad de M urcia. Facultad de Economía y Empresa \\ Departamento de Sociología y Política Social \\ M urcia \\ psvera@fcu.um.es
}

\section{Resumen}

La complementariedad de enfoques entre la economía y la sociología referido a los mayores es necesaria desde el punto de vista conceptual y metodológico. La sociología de la vejez y la economía de la vejez deberán buscar su punto de encuentro, no tanto en la perspectiva macro del envejecimiento demográfico y sus costos y consecuencias económicas, sino en un nivel cotidiano, privado y familiar, prestándole atención a la economía no monetaria. Se analizan desde esta perspectiva los distintos tipos de trabajos existentes, así como algunos de los hechos económicos más relevantes en la vida del mayor: trabajo, atención, situación familiar y económica, consumo y ahorro.

Palabras clave: ahorro, consumo, economía de la vejez, economía no monetaria, sociología de la vejez.

Abstract. Sociology of Aging versus Economics of Aging

The complement of approaches between the economy and the sociology related to the ederly is necesary fron the conceptual and methodological point of view. The Sociology of Aging and Economics Aging must find their place at some point, not only fron the macro perspective of demographically growing old and its costs and economic conse cuences, but also in the daily, private and family levels, paying attention to the «no monetary» economy. The different types of existing research works and some of the most inportant economic facts in the life of the ederly are analyzeed from this perspective: work, attention, familiy and economical situation, spending and saving.

Key words: economics aging, no monetary economy, saving, sociology of aging, spending.

\begin{aligned} & \multicolumn{2}{c}{ Sumario } \\ & Introducción Los mayores, la cultura económica \\ & Empleo y jubilación y el ahorro \\ & y atención al mayor La economía, los mayores y el género \\ & ómica de los mayores Los mayores y el juego \\ & mayores y el consumo La publicidad y los mayores \\ & Bibliografía \end{aligned}




\section{Introducción}

L a complementariedad de enfoques entre la economía y la sociología referido a los mayores, es necesaria desde el punto de vista conceptual y metodológico, con independencia de que, a la hora de estudiar lo económico en los mayores, haya sido la ciencia económica frente a la sociología quien haya implantado su primacía y hecho valer su perspectiva, cuando es deseable una mayor complementariedad entre estas disciplinas a la hora de estudiar a los mayores. Como señala una experta (Solé, 1993: 157): «el desarrollo metodológico de la economía puede ser rentable en su implicación a los temas sociológicos. Y a la inversa, la sociología puede ayudar a relativizar el enfoque económico a problemas que son, fundamentalmente, sociales; al completar el análisis económico tendente a la unicidad, con la comparación sistemática y confrontación entre diversos casos empíricos de un mismo problema».

D esde los pioneros trabajos de Shulz (1973), la producción de trabajos de corte económico sobre los mayores han proliferado sobre todo desde un nivel macroeconómico, pero frecuentemente falta por conocerse mejor el nivel micro, que es donde se cocina y se gesta la más de veces el comportamiento económico y no económico del mayor, y en donde hay unos espacios de difícil delimitación y de interacción recíproca entre lo económico y lo no económico. Es ahí donde la sociología de la vejez debe de intervenir, para poner en relación al mayor, con dos ambitos: el social y el económico, y con dos niveles: el macro y el micro.

La sociología de la vejez y la economía de la vejez deberán buscar su punto de encuentro, no tanto en la perspectiva macro del envejecimiento demográfico y sus costos y consecuencias económicas, sino en un nivel cotidiano, privado y familiar. D esde esta perspectiva y punto de encuentro, vamos a poder abordar y entender mucho mejor «lo económico» en los mayores. Varias son las causas: a) Porque «o económico» ocupa un lugar primigenio en la vida cotidiana del sujeto mayor desde el mismo hontanar de la jubilación (y aún antes), pasando por sus conversaciones cotidianas y sus propias circunstancias (salud, viudedad, herencia, situación familiar, etc.) que están marcando unas actitudes muy mediatizadas por lo económico. b) Porque el envejecimiento demográfico ha hegemonizado la perspectiva económica de los mayores. Esta tarea, en la que han entrado de lleno profesionales de la economía, siendo interesante y necesaria, sin embargo suele estar presidida por discursos economicistas y frecuentemente hipercríticos (cuando no catastrofistas) con el futuro del sistema público de pensiones (Barea, 1988 y 1993; Segura, 1988; Fernández M oreno, 1993; Torres López, 1996). c) Porque en el análisis de los mayores y la economía, está siendo la ciencia económica en sus diferentes campos (teoría, marketing, mercadotecnia, investigación de mercados, etc. ), quien está hegemonizando el análisis - y el discurso- sobre los mayores y la economía, no habiendo una correspondencia similar por parte de la sociología de la vejez, ni siquiera de otros ámbitos o campos de estu- 
dio de la sociología (sociología económica, sociología del consumo); e incluso los estudios de consumo y de mercado sobre mayores no tienen en España aún la relevancia que le correspondería, tanto por el volumen creciente del colectivo y su mejora de poder adquisitivo (sin olvidar su alta capacidad de ahorro), como por sus efectos e influencia benefactora para la economía a diferentes niveles, tanto para las domésticas o familiares como para la públicas (banca, administración). Faltan por estudiarse, entre otros campos, aspectos tales como el empresariado mayor. d) Porque dentro de la sociología de la vejez es básico introducir «lo económico» incluso con más énfasis del que se hace, puesto que esta perspectiva explica muchas de las conductas, percepciones y valores del mayor.

Por último, si hacemos un repaso de los estudios y de las monografías producidos en España sobre mayores desde la perspectiva sociológica que incluyan en su análisis «lo económico» como hecho central, éstos son realmente escasos, y los que hay, o lo hacen desde una perspectiva macroeconómica o incluyen «lo económico» como hecho influyente de otros objetos de estudio o de otras áreas de interés, quedando, en cualquier caso, todavía muchos aspectos de «lo económico» de los mayores por abordar desde la perspectiva sociológica. Por tanto - y a modo de resumen - podemos decir que en los estudios socioeconómicos sobre mayores ocurren los siguientes hechos:

1. La dominancia de una perspectiva ideológica (sin negar que hayan varias en juego).

2. La hegemonía de lo «económico» sobre lo «sociológico», y de lo «social» sobre lo «sociológico».

3. La preeminencia de lo macro sobre lo micro.

4. La diversidad y dispersión de los objetos de estudio.

5. La falta de definición y de clarificación conceptual sobre los efectos benefactores de las conductas y los comportamientos del mayor sobre la economía.

6. La servidumbre de otros estudios que incluyen «lo económico» directa 0 tangencialmente como una variable discreta, y que están referidos al comportamiento de diferentes grupos etáneos, en donde suele incluirse al grupo de mayores de 65 años.

7. La falta de articulación y posiblemente de permeabilidad en este campo, de la sociología de la vejez con otras sociologías: sociología de la salud, de la familia, de la población, industrial y del trabajo, del género, de la vida cotidiana, del consumo, del ocio, etc.

8. La dependencia de «lo social», de «lo económico»; y la dominancia de la perspectiva del bienestar social y de la política social (estudios sobre pobreza) sobre los estudios básicos sobre comportamiento y valores económicos del mayor.

Poniendo, pues, de relieve y partiendo de la premisa de la hegemonía de la sconomía sobre la sociología en cuanto al estudio de lo económico en los 
mayores, podríamos hacer una clasificación aproximativa a las clases y tipos de investigaciones y/o informes sobre los mayores que incluyen lo económico. Con independencia de que se trate de estudios básicos o aplicados, «sobre» mayores o «a» mayores - esto es, que sean sujeto u objeto- , cabrían diferentes clasificaciones, pues son multitud los estudios que pueden incluir entre sus variables la edad y la economía, ésta última en sus muy diferentes ámbitos y facetas. La clasificación que sigue es descriptiva y atiende al tipo de trabajos publicados y conocidos. $\mathrm{H}$ abría que observar que muchos de los trabajos podrían compartir posición en diferente tipo:

1. Estudios sobre los efectos económicos del envejecimiento demográfico.

2. Estudios sobre la situación económica de los mayores.

3. Estudios sobre bienestar social, necesidades, calidad de vida y/o políticas sociales para los mayores.

4. Estudios cuyo objeto de estudio no son los mayores y que incorporan lo económico entre sus partes, pero que incluyen al grupo de mayores (más de 65 años) entre los grupos etáneos.

5. Estudios de opinión sobre la vejez y los mayores (percepción de la misma) que incluyen lo económico como variable, y que están realizados a sujetos menores de 65 años, o a los propios mayores.

6. Estudios que tratan sobre la economía en general o sobre distintos aspectos de la misma (actitudes, percepciones, valoración, etc.; sobre el empleo, la situación y la política económica, la fiscalidad, etc.) o sobre al gunos de los servicios para los mayores (salud, servicios sociales, etc.); o sobre su situación económica en particular (con relación a los demás miembros de la sociedad, o en relación con el resto de mayores ayer y hoy, o con relación a ellos mismos en periodos anteriores: cuando trabajaban, cuando se jubilaron o desde entonces hasta ahora).

7. Estudios sobre la jubilación y sus implicaciones con la vejez y la economía; o sobre jubilación y la sociedad industrial

8. Estudios sobre políticas sociales para mayores, su costo y/o sus efectos económicos.

9. Estudios de naturaleza diversa (salud) sobre los mayores y que incluyen lo económico entre sus apartados o como variable más o menos dependiente.

10. Estudios sobre la conducta económica del mayor en diferentes facetas: consumo, ahorro, vivienda, herencia, etc.; o sobre ámbitos de la actividad del mayor que, sin ser económicos, redundan en la economía (papel de los abuelos, vida cotidiana, economía no monetaria, etc.).

D e todos los anteriores grupos sobre investigaciones sobre los mayores y la economía, el menos numeroso es el último. Sería deseable, pues, que en los próximos años, la incipiente (y dinámica) sociología de la vejez española no pierda de vista una serie de campos de atención, que general mente se gestan a un nivel microsociológico y en el ámbito de la vida cotidiana del mayor, 
siendo particularmente interesante una reflexión de toda una serie de espacios relacionados con la economía no monetarizada. $\mathrm{H}$ ay que observar que estos estudios sobre economía no monetaria incluirían no sólo al mayor, sino también a la familia y a todo el sector informal y voluntariado.

La anterior observación es particularmente interesante si nos referimos a los trabajos que ponen en relación mayores y economía. U na parte importante de los estudios al respecto lo son sobre el cuidado formal (servicios sociales públicos y privados), pero no hay que olvidar el crecimiento de la atención informal, la cual a su vez hay que verla por activa y por pasiva, en la parte emergida y en la parte sumergida del iceberg, pues hay que considerar a los mayores como sujeto de la atención (al nieto, a los hijos, a sus propios padres, etc.) o como objeto de la misma (papel cuidador de la familia en la vejez y en la enfermedad).

Por citar alguno de los temas a los que la sociología de la vejez debería prestar una mayor atención en los próximos años - o hacerlo en su caso con más énfasis- , citaremos entre otros los siguientes: uso del tiempo, las actitudes ante el ahorro, la herencia, el consumo, el medio ambiente y el juego por parte de los mayores. La cultura económica de los mayores y el aprendizaje de la misma. El papel de la pensión en las economías domésticas de los hogares en los que viven mayores. El papel de la vivienda y de la herencia. La planificación de la vejez. El grado de autonomía de los mayores en las decisiones económicas. En suma: el papel de «lo económico» en la vida cotidiana del mayor. Es verdad que muchas de estas situaciones se gestan en el seno del hogar y de la familia, por lo cual no habrá que perder de vista la situación objetiva, así como tampoco el grado de dependencia y de vinculación - objetiva y subjetiva - del mayor con sus familias.

En la línea anterior y de cara a enriquecer los estudios de sociología de la vejez desde «o económico», seria muy fecundo el retomar las interesantes aportaciones que la denominada economía no monetarizada puede hacer al conocimiento de los mayores. Las aportaciones de los abuelos a la economía no monetaria del hogar están siendo puestas de relieve por diferentes autores (I glesias de U ssel, 1998; Bazo, 1993) Estas aportaciones han quedado al margen de la ciencia económica, al no ser estudiadas por los economistas, pues, como señala el economista Viner: economía es lo que estudian los economistas (Viner, 1969), y han sido estudiadas gracias sobre todo a la sociología de la familia, cuya recuperación se debe en gran parte a los estudios sociológicos sobre la mujer. D entro de la economía no monetaria referida a los mayores, es particularmente importante y sería deseable un mejor conocimiento sobre el uso del tiempo, muy particularmente aquél que dedican los mayores a realizar tareas domésticas ligadas al hogar de los hijos, que van desde el cuidado, la recogida y la custodia de los nietos hasta la realización de pequeñas tareas y encargos. D e igual forma (y con independencia de la familia), sería interesante conocer los efectos que sobre la sociedad tienen elementos económico-culturales de la cultura de los mayores: ahorro, consejos, conciencia de donde venimos, solidaridad económica y/o social. 
U no de los temas de extraordinario interés sobre los mayores y los económico, como hemos señalado, es todo lo concerniente a la economía no monetaria. Tal como ponen de relieve dos especialistas en la materia, las demandas de trabajo no monetarizado (DET RAN M E) de los ancianos son particularmente importantes: «D espués del retiro, no sólo cambia para el jubilado la relación con los componentes monetarios (origen, cuantía, regularidad) de su posición económica. También cambia su relación con la asignación y uso de recursos no monetarios, especialmente el tiempo. D e golpe, los jubilados acceden a grandes cantidades de tiempo disponible para actividades ajenas al empleo, y esto constituye un dato económico, no monetario de primera magnitud» (H errera, D urán, 1995: 117). Como señalan estas autoras «El sujeto prototípico de la economía de mercado es el que cambia su trabajo por una cantidad de dinero que le permite comprar o acumular bienes y servicios por un valor global equivalente. Pero el jubilado, excluido por ley del mercado laboral, no puede entenderse desde este marco interpretativo básico: en ese momento de su vida no hay ya una correspondencia directa entre el valor (a precios de mercado) de lo que entrega y de lo que recibe, y hace falta recurrir a otros criterios no exclusivamente intercambistas, para entender su estatuto económico (o.c.: 118).

Si hubiera que delimitar campos dentro de la economía no monetaria, éstos serían particularmente interesantes al referirnos a los mayores. En opinión de un experto (Fernández Enguita, 1998: 53-61), los campos de la economía no monetaria serían, según orden de importancia, tres: el primero es el de la producción doméstica (que generalmente se produce en el seno de la familia). El segundo campo estará constituido por los trabajos y las transferencias públicas (servicio militar, prestación social sustitutoria, etc.), ya que a lo largo de una vida un sujeto realiza determinadas aportaciones al Estado (impuestos, prestaciones) y recibe determinadas transferencias (que suelen ser servicios: educación, sanidad, carreteras o pensiones no contributivas). El tercer y último campo definidor de la economía no monetaria será el denominado economía comunitaria (voluntariado, ayuda mutua). En el caso de los mayores, estos tres ámbitos de la economía no monetaria son particularmente relevantes, dándose la circunstancia de un cierto entreveramiento entre los mismos a la hora de referirnos a los mayores y produciéndose igualmente un nexo más o menos cómplice entre el Estado y la familia, y entre ésta y los particulares. Como señala un experto en la materia, se trata de la relación entre los grupos domésticos y las comunidades políticas, y entre las redes inclusivas y las voluntarias (Fernández Enguita, 1993).

Las necesidades económicas y la calidad de vida del mayor, teniendo elementos comunes con otros grupos o colectivos, también tendrán su especificidad. Como observan algunos expertos: «desde el momento que tratamos de conocer la calidad de vida de grupos que pueden presentar problemas específicos y que, por lo tanto, pueden requerir una atención específica, se nos impone considerar la calidad de vida desde una teoría sustantivista que aco- 
ja tanto a indicadores objetivos como subjetivos» (Aguiar, Pérez Yruela, Serrano, 1995: 15).

Un lugar de encuentro entre la solciología de la vejez y la economía de la vejez es la economía política, donde se entrevera el debate ideológico sobre el envejecimiento. Como señala un experto, «las concepciones - sobre el envejecimiento- que se enfrentan son antagónicas y en modo al guno objetivas, en la medida en que los principios en juego son de naturaleza política y trascienden la simple marcha de los acontecimientos (Cárceles Breis, 1996: 204).

Aunque, como hemos señalado, muchos de los trabajos que abordan los aspectos económicos de la vejez son trabajos de economía de la vejez. Sin embargo, muchos de esos estudios económicos incorporan dimensiones sociales (sobre pensiones, pobreza, marginación, etc.). O tros estudios, más de corte estrictamente económico, hacen incursión en las esferas de atención a los mayores, introduciendo por ejemplo determinados modelos de análisis económicos (coste-beneficio: Pinto Prades, 1993: 289-322), o simplemente se hacen distintas valoraciones de carácter económico, tanto sobre la situación objetiva de los mayores, como sobre el gasto social destinado a estos colectivos, bien sea a nivel nacional o en determinadas comunidades autónomas, dentro del contexto de planes gerontológicos concretos (G obierno de $\mathrm{N}$ avarra, 1997). Pero en general, a la economía, el estudio de fenómenos como los empresarios mayores como agentes económicos directos, o en sus facetas de transmisión de experiencia a las nuevas generaciones dentro y fuera de la empresa, le interesan muy relativamente. Sirvan de ejemplo, los excelentes trabajos sobre el empresario mayor agrícola realizados por Ángel Paniagua (1997) para el C SIC.

D esde la perspectiva de la sociología de la vejez, en general los enfoques de la economía política han condicionado bastante su trayectoria, pero en general hay una tendencia a ver lo global u holístico y olvidar lo individual y cotidiano, aunque, obvio es decirlo, lo segundo difícilmente podrá ser comprendido sin el prisma térico que aporta el primero.

En el caso más concreto de la sociología de la vejez en España, o desde diferentes estudios sociológicos que, aún proviniendo de otros ámbitos de esta disciplina, incorporan en sus análisis la incidencia de un determinado fenómeno económico en la población mayor, o que en su caso estudian la situación, el comportamiento o las actitudes de los mayores de su situación general o particular; la dimensión económica ha estado presente, bien sea de manera directa o implícita. D esde el pionero informe GAUR (1975: 265371), donde ya estudiaban los recursos económicos de los mayores, 0 en algunos de los informes FO ESSA (1994, vol. 2); donde, desde una perspectiva macro, se puede observar la evolución del gasto en pensiones con relación a otros capítulos de protección social, echándose en falta en otros de estos informes sociológicos (FOESSA, 1976) referencias explícitas a la edad en temas de orden económico (consumo, ahorro, recursos económicos, consumo farmacéutico, etc.). 
M ención explícita merecen los estudios del $C$ entro de Investigaciones de la Realidad Social (CIRES), donde se puede obtener información de rele vancia económica sobre el comportamiento del grupo de mayores de 65 años - junto a otros grupos etáneos- : (CIRES, 1992: 643-694), o en los posteriores CIRES (1994: 806-872) donde se tienen referencias explícitas sobre la cultura económica (y política) de los mayores; o CIRES (1995), donde se pue de obtener información sobre las actitudes socioeconómicas básicas (0.C.: 860-884); sobre la política económica y laboral (o.c.: 885-906); o sobre evaluación de la situación económica de España. Todos estos estudios incluyen al grupo de mayores de 65 años, donde se contemplan temas de interés y rele vancia económica para diferentes grupos etáneos donde se incluye, pues, a los mayores, siendo de especial relevancia a los efectos del presente artículo (lo económico y los mayores), lo concerniente al uso del tiempo (CIRES, 1997: 491-671), a las actitudes socioeconómicas básicas (0.C.: 860-885), opiniones sobre política económica y laboral (0.c.: 860-885), o la evaluación de la situación económica personal y del país (0.c.: 894-1006). En el mismo informe merece la pena destacarse el muy interesante capítulo dedicado monográficamente a los mayores (0.c.: 775-856) en el que igualmente se abordan temas de relevancia económica de los mayores y su situación real en sus actividades, hábitos, trabajo, ocio y calidad de vida.

M erecería ser citado aparte el C entro de Investigaciones Sociológicas (CIS), puesto que muchos de sus estudios y encuestas abordan directamente temas económicos, y donde se pueden aislar los datos y las opiniones de los mayores. En este sentido (datos de opinión), merecen ser citados entre los estudios más recientes del CIS - aunque sería de gran interés seguir la evolución de estos trabajos económicos que tengan en cuenta al grupo de edad de mayores de 65 años desde el año 1965 hasta la fecha- , por tratarse de temas estrictamente económicos, los estudios siguientes: sobre «0 pinión pública y política fiscal» (estudios números: 2.187 de julio de 1995; 2.219 de julio de 1996; 2.253 de julio de 1997); sobre «Cultura económica de los españoles» (estudio núm. 2.224 de octubre-noviembre de 1996); sobre « ngre so, gasto y ahorro familiar» (estudio núm. 2.222 de septiembre de 1996); sobre «C omportamiento económico de los españoles: consumo y ahorro» (estudio 2.251 de julio de 1997); sobre «Equipamiento de los hogares españoles» (estudio núm. 2.218 de julio de 1996); sobre «D efensa del consumidor» en colaboración con el M inisterio de Sanidad y Consumo (estudio núm. 2.186 de diciembre del 1995); sobre «Trabajo» (estudio núm. 2.235 de febrero de 1997); sobre «economía sumergida» (estudios números 2.245 de abril-mayo de 1997 y 2.249 de junio de 1997). O tras encuestas y trabajos de investigación, tambien del CIS, abordan temas diferentes, que sin ser estrictamente económicos, tienen relevancia o hacen mención a lo económico - pudiendo ser igualmente aisladas las opiniones de los mayores.

En este otro grupo de trabajos del CIS, merecerían citarse entre otros, los trabajos sobre las condiciones de vida (Cruz, C obo, 1990) (o sobre el mayor como cliente de las residencias (Kaufmann y otros, 1997); o sobre otros 
temas, que abordan inevitablemente aspectos económicos o de relevancia económica, tales como - y a modo de ejemplo- la dinámica generacional y el sistema de valores de los españoles (Andrés 0 rizo, 1995), las actitudes ante la desigualdad en España (N oya, Vallejos, 1995), ante la economía sumergida (Ruesca, 1997), sobre representaciones de la sociedad española (Cruz, 1994) o incluso sobre el comportamiento ante temas como las vacaciones (Azofra M árquez, 1996). También consideramos de interés y relevancia económica para entender al consumidor mayor, el estudio sobre «Percepción del fraude social» (estudio núm. 2.079 de enero de 1994); o los más recientes sobre «H ábitos y comportamientos ante la TV» (estudio núm. 2.272, de enero de 1998) o sobre «Tiempo libre y hábitos de lectura» (estudio núm. 2.280 de marzo de 1998).

D esde la perspectiva económica y continuando con los trabajos del CIS de corte económico con incidencia en los mayores, merece citarse el estudio sobre «A poyo informal en las personas mayores» (estudio núm. 2.072), pero se echa en falta una actualización de las estudios sobre los juegos de azar (de gran interés en la vida del mayor), quedando ya muy lejanos los estudios números 1.024 y 1.144 sobre loterías (abril 1966 y marzo de 1978 respectivamente).

I gualmente, se están produciendo diferentes trabajos sobre la pobreza de los mayores (Paniagua, 1993), sobre sus necesidades (v. g: Pérez O rtiz, 1988), sobre su calidad de vida (Sáez, 1997), sobre el bienestar (M oragas, 1981 y 1991) y/o sobre su situación económica en general (C ano Lozano, 1990), o sobre la situación económica de colectivos concretos, como es el caso de las viudas (v. g: Salvador, 1997; Bleda, Centelles, Uña, 1998) o de los mayores en el medio rural (Paniagua, 1997; García Sanz, 1997).

Todos los anteriores trabajos - tanto desde una perspectiva estatal como regional- nos están permitiendo conocer con mayor detalle la situación económica de los mayores en España. A esa contribución tampoco le son aje nos algunos importantes trabajos sobre una serie de aspectos que, sin ser económicos estrictamente, sí que están entreverados con la economía. Entre éstos baste citar: «El papel de los cuidadores de mayores» (Bazo, 1991; Rodríguez, 1991 y 1994: 57-98, 104-199).

El problema, en cualquier caso, hay que verlo por activa y por pasiva. Esto es: el anciano como cuidador y el anciano cuidado. El papel de la familia y particularmente de la mujer en el cuidado de los ancianos, y a la inversa el papel de los abuelos en la familia, o incluso las políticas de familia y su incidencia en los mayores, temas estos en los que viene trabajando entre otros el profesor I glesias de U ssel (1998). Pese a los importantes cambios que ha habido en la estructura familiar española, la familia continúa siendo el principal pilar de apoyo a la vejez en España. Para el profesor Julio I glesias de U ssel, la familia (1998: 260) y en concreto la mujer es, en España, el verdadero M inisterio de Asuntos Sociales. En opinión del citado profesor (I glesias de U ssel, 1996: 35): «N o se conoce bien en España el papel que están desempeñando los abuelos en la socialización de los nietos. Pero lo que sí es un 
hecho, es que una parte importante de la modernización de la sociedad y de la incorporación de la mujer al trabajo extradoméstico se está realizando gracias al trabajo de los abuelos y abuelas; una especie de trabajo sumergido que permite el funcionamiento del hogar familiar. Ya la emigración de los años sesenta hizo recaer la crianza de los hijos por parte de los abuelos. $\mathrm{H}$ oy la atención y cuidado de los niños, así como su traslado a los centros escolares, tareas domésticas, atención en situaciones de enfermedad, custodia de vacaciones (añado: y salidas de noche de viernes o sábado de sus hijos), recaen en gran parte sobre las abuelas y los abuelos en la sociedad española, cuando trabajan el padre y la madre». O tros autores hablan del sector informal y el voluntariado en un sentido más amplio, y que al tratarse de un trabajo no remunerado tienen unos efectos importantes sobre la economía en sus funciones de atención a los mayores. En palabras de un experto, el sector informal es «aquel que consiste en la provisión de asistencia social y sanitaria por parte de familiares, amigos, y vecinos» (J ohnson, 1990: 97). Todas estas actividades no monetarias, sin duda tienen unos extraordinarios efectos en las economías domésticas y en la economía nacional. 0 tros autores han puesto de relieve la importancia de la familia y de los mayores en la creación de la pequeña y mediana empresa en España (Pérez Díaz, 1996: 61).

$O$ tros trabajos han puesto énfasis en el conflicto entre generaciones y la importancia de la seguridad financiera en la situación social de los mayores (D íaz Casanova, 1989), o sobre la incidencia de la sociedad industrial en la jubilación y de ésta en el status del anciano (Sánchez Vera, 1993b). I gualmente, es de gran interés la incorporación de la variable espacio-cultural, mereciendo ser citados, entre otros, los trabajos sobre el anciano rural del profesor G arcía Sanz (G arcía Sanz, 1995) o sobre el envejecimiento del empresariado agrícola (Paniagua, 1997: 87-112). Siendo también de extraordinario interés para conocer «lo económico», algunos trabajos sobre percepción de las políticas sociales de mayores (Bleda, 1997).

Aunque desde una perspectiva más económica, se han producido en España trabajos interesantes y de gran utilidad sobre las actividades económicas de los mayores, mereciendo destacarse a tal efecto el pionero y paradigmático trabajo - a los efectos citados- que Seniors Españoles para la C ooperación Técnica (SEC OT, 1995), sacó bajo el patrocinio del Central H ispano, en el cual se abordan, entre otros, temas tan interesantes como el mercado de trabajo, las rentas, el gasto, el mercado financiero o el mercado inmobiliario, todo ello referido a los mayores. Algunos de estos temas, tales como la herencia y su papel en el seno de la familia, el consumo de los mayores, la planificación de la vejez, el ahorro y la inversión, etc., merecerían una atención mayor - tal como hemos señalado- por parte de la sociología de la vejez en España.

En los últimos años se han producido trabajos de reconocimiento objetivo sobre la situación económica de los mayores (IN SER SO, 1995); de los trabajadores mayores (Fernández Enguita, 1997), o encuestas de diferente procedencia sobre los mayores que han contemplado y contemplan aspectos 
relacionados con la situación económica particular o general de España, o sobre «o económico» como una de las variables (CIS, 1991; CIRES, 1992, 1994 y 1995; FO ESSA, 1994; D íez N icolás, 1996; D e M iguel, 1996, 1997, 1998).

C omo habíamos enunciado más arriba, muchos de los trabajos e investigaciones socioeconómicas producidas en España, tienen la servidumbre de la perspectiva del bienestar social o incluso de las políticas sociales. C omo señala una experta en la materia: «entre los grandes temas relacionados con la vejez, el tocante al bienestar económico, a la situación económica, está adquiriendo un gran predicamento desde una perspectiva socioeconómica. Existe una razón de peso para que esto sea así: a fin de cuentas, la variable económica condicionará formas y estilos de vida [... ] Pero, paralelamente, la situación económica de la vejez adquiere una enorme relevancia adicional cuando es relacionada con los modelos públicos de bienestar que ordenan buena parte de Europa y también de España» (Pérez O rtiz, 1998: 13). También es verdad, que muchos de los trabajos que se han producido sobre vejez y economía, lo han sido sobre pobreza (Fundación Argentaria 1993) o sobre políticas sociales (Rodríguez Cabrero, 1989 y 1994). Trabajos, a la sazón, que están sobradamente justificados en el caso español, pero que un cierto abuso de la asociación entre vejez y marginalidad, no ayuda al análisis objetivo de la realidad. C omo señala certeramente Lourdes Pérez O rtiz (p. 12), esto ha contribuido a desfigurar en cierta forma el perfil del anciano, pues esos trabajos están más centrados en disciplinas relacionadas con la integración social de la marginación que con el análisis de detalle de todo su contenido. En cualquier caso, este tipo de trabajos sobre la situación económica de los mayores siguen siendo necesarios, pues existen problemas de fuentes fidedignas, pues, como señala una de nuestras más destacadas especialistas en la materia: «queda mucho por investigar si se pretende poner en claro el auténtico soporte material y económico de la situación social de la vejez» (Pérez 0 rtiz, 0.c.: 13).

D e cualquier manera, - tal como referimos anteriormente- Ios trabajos más divulgados y conocidos son aquéllos que reflexionan sobre los aspectos y efectos económicos del envejecimiento demográfico, en donde son multitud los estudios e informes que aluden a los efectos negativos, no deseados y/o perversos del mismo sobre el sistema público de pensiones, sobre la Seguridad Social y/o sobre la crisis de los estados de bienestar, o sobre la situación de las pensiones y de las prestaciones por desempleo en su situación actual (VV.AA., 1996) o exclusivamente de las pensiones desde una perspectiva marcadamente prospectiva a partir de diferentes escenarios e imágenes $(\mathrm{H}$ erce, 1998: 253-270). El debate teórico-ideológico sobre el Estado del bienestar y su futuro es el fondo del problema y, como es sabido es uno de los grandes problemas desde la perspectiva económica y política. Son multitud los informes y estudios que se han venido produciendo en los últimos años (y décadas) al respecto. Pero referido al caso español, y con especial referencia al envejecimiento demográfico y el sistema público de pensiones, se han publicado una serie de debates vinculados a la reforma del sistema de pensiones, destacando entre éstos el conocido informe de la Fundación de Estu- 
dios de economía Aplicada (FEDEA), o el de la Fundación BBV dirigido por el profesor José Barea (1995), donde en general se viene a concluir en la inviabilidad del sistema público de la Seguridad Social. Estos informes (y otros), se sustentan en el principio de la falta de equidad intergeneracional e intrageneracional (regímenes especiales). El argumento demográfico es, junto al económico, la base que para al gunos trabajos justificaría una reforma del sistema público de pensiones. A modo de ejemplo y por citar alguno de marcado carácter sociológico, es el capítulo dedicado a la crisis financiera en el sistema de pensiones, realizado en el informe anual sobre España de la Fundación Encuentro (CECS, 1995: 383-432).

0 tros trabajos de marcado sesgo demográfico hacen igualmente intere santes referencias de carácter social y económico sobre el efecto de la estructura de edades sobre la economía referido a al gunas teorías (efecto Preston y efecto Easterlin) y sobre la situación económica de los mayores en España (Pérez Díaz, 1996).

Pero como certeramente han puesto de relieve diferentes especialistas (Cabré, 1993), y que con posterioridad se ha visto en parte refrendado en el denominado Pacto de Toledo de 1995, la carga que pueden representar las personas de edad sobre la población activa dependerá tanto o más de factores socioeconómicos y legales que de elementos demográficos. D icho de otra manera, las edades de entrada y salida de la actividad, los niveles de empleo y ocupación (muy particularmente), esto es: el número de cotizantes a la Seguridad Social, la ocupación femenina, la economía sumergida (que se escapa a la cotización), la productividad, los inmigrantes, las diferencias entre los niveles salariales de las personas jóvenes (base para la cotización) y de las personas mayores (base para la jubilación), tienen una mayor importancia que la sola relación numérica entre grupos de edad. Como señala la autora antes citada referido al uso abusivo y simplista de las tasas de dependencia demográfica (p. 17-20): «sería, por tanto, conveniente estudiar mejor la incidencia de posibles variaciones futuras en todos los factores anteriores, evitando la simplificación abusiva [... ] Esto distorsiona la realidad, puesto que los jubilados suelen disponer de medios de vida propios y han pagado sus pensiones por anticipado, mediante la cotización y la tributación. 0 tra cosa es la utilización social que en su momento se haya dado a dichas contribuciones. Se trata, pues, de un problema de gestión de los sistemas de previsión y no de un problema demográfico».

D e igual manera, otro de los aspectos económicos tratados sobre el envejecimiento demográfico es el hecho de que el incremento en los gastos sociales de los países desarrollados, ha ido acompañado de un crecimiento paralelo a los gastos en vejez (algunos se atreven a decir que incluso a costa de las necesidades de otros grupos). Este fenómeno es el que se ha denominado el «encanecimiento» de los presupuestos sociales (Gulliemard, 1990: 107), y que ha sido utilizado a veces en contra de los propios mayores.

Uno de los temas abordados frecuentemente cuando se habla de los mayores y la economía es el del gasto o consumo sanitario (hospitalario y farma- 
céutico), que, como es sabido, ha crecido extraordinariamente en España, particularmente en el caso de los ancianos. Esto tiene una lógica relativa, si tomamos en consideración que los gastos sanitarios evolucionan a lo largo de la vida del sujeto en forma de $U$, esto es, un consumo muy intenso en los primeros años de vida y en la vejez (Pérez 0 rtiz, o.c.: 243 y s).

Algunos estudios aprovechan interesadamente este hecho para denostar y desacreditar el gasto sanitario (hospitalario y sobre todo farmacéutico) unido al envejecimiento demográfico. Tales extremos nos parecen contraproducentes, pues existen muchos factores que están provocando un gasto sanitario excesivo y que poco tiene que ver con el envejecimiento demográfico. Entre estos factores al gunos se pueden citar básicamente: La propia estructura del sistema público de salud que orienta a los ancianos hacia las formas de asistencia más onerosas, fundamentalmente la hospitalización, que fre cuentemente son las menos apropiadas para su cuidado, así como el cambio de funciones que se dio en la medicina hospitalaria durante los sesenta y los setenta, que incrementó la medicina especializada en detrimento de la función de acogida; así, la carencia de estructuras al ternativas de menor coste y, a la vez, más apropiadas para el cuidado sociosanitario de los ancianos, como los centros de día, las unidades geriátricas o las residencias asistidas. Como pone de relieve una especialista (Guillemard, 1990: 77, 103), la cobertura pública prefiere el hospital y la medicina ambulatoria, convierte a su vez este tipo de asistencia en la más atractiva para los ancianos y sus familiares, así como la falta de coordinación entre los distintos sectores de la atención, en especial la ruptura entre la atención sanitaria y la dimensión social. Éste es, como hemos visto, uno de los principales objetivos del Plan G erontológico $\mathrm{N}$ acional de 1990. Es conocido el número de ancianos hospitalizados indebidamente. Según la estimación que hizo el IN SERSO (1990: 59), la proporción de ancianos hospitalizados indebidamente en España era del 20\% del total. O tros autores ponen de relieve el uso de que las consultas y los servicios de urgencia hospitalaria son utilizadas con frecuencia por los ancianos como servicios de ayuda psicológica y como paliativos de problemas de soledad e incomunicación. 0 tro tanto ocurre con los ancianos internados en servicios psiquiátricos. 0 tro de los temas permanentemente en el candelero es el conocido excesivo gasto farmacéutico de los ancianos. D esde el conocido informe realizado por el recientemente fallecido Abril $M$ artorell realizado en el año 1990, hasta las recientes medidas del gobierno sobre el medicamento, que, según una encuesta reciente dirigida por Amando de M iguel, encuentra un alto rechazo - no podía ser de otra manera, aunque con muchos matices - entre los pensionistas, ha sido un tema casi recurrente (D e M iguel, 1997: 55). Como revela igualmente la Encuesta N acional de Salud (M inisterio de Sanidad y C onsumo, 1993), el consumo de medicamentos se incre menta considerablemente en el grupo de 65 y más años.

0 tros autores aluden a esta forma de $U$ para llamar la atención sobre la mudanza que se produjo en Europa y Estados Unidos en la estructura de edades y en la distribución de la pobreza. Así, señalaba Samuel Preston 
(Preston, 1984: 36-41) que entre 1960 y 1980 en Estados U nidos había aumentado un $54 \%$ el número de personas de edad avanzada, y descendido en un $7 \%$ el de niños. D ándose la paradoja que mientras los mayores habían mejorado sensiblemente su bienestar (incluido el bienestar económico), los niños habían visto empeorar su situación relativa. Así, mientras que en los años setenta era entre los mayores donde se observaba el máximo porcentaje de pobreza, ésta se dirigió hacia los menores de catorce años al inicio de los ochenta, siendo ello debido a que los mayores en Estados U nidos aumentaron sus ingresos más deprisa que los jóvenes (Pérez Díaz, 1996: 34-38).

Si bien es cierto que la jubilación suele repercutir en la movilidad social descente del mayor, sin embargo no necesariamente tiene que ser así. Un asunto ligado al anterior es la ligazón entre la edad y la estructura social por lo que se refiere a los mayores. A tal efecto es particularmente importante prestar atención a un doble hecho que, aunque con algunos matices (deben tenerse en cuenta importantes diferencias de partida), puede resultar paradigmático en el caso español: de una parte, la tendencia a la aproximación en cuanto a poderes adquisitivos entre los mayores y otros grupos etáneos (intergeneracionalidad), y, de otra parte, la tendencia a la aproximación económica entre los propios mayores (intrageneracionalidad). En este último caso, Ia limitación en la pensión máxima, la elevación en la mínima, y la mejora notable en la situación económica de ciertos tipos de pensiones, por ejemplo las de viudedad ( $A B C: 3 / 11 / 98$ ), han igualado la situación endógena o intrageneracional de los mayores. En cualquier caso, tanto en la faceta «intergeneracional» como en la «intrageneracional», cabrían muchos matices - y algunos contrapuestos- y donde factores como la capacidad de previsión, la racionalidad y acierto en la decisión económica y el género de vida serán variables a ligar al propio poder adquisitivo.

En cualquier caso, hasta ahora los gastos sociales han sido fruto de decisiones políticas que han actuado en diferentes frentes: pensiones, servicios sociales, salud, etc. Pero también hay que tener en cuenta que los mayores son una parte importante y creciente en el censo electoral, y todo hace indicar que los mayores presentan una mayor fidelidad de voto hacia el partido que decidieron votar (M oncada, 1998: 87), aunque no sea fácil decir si fue la edad propiamente dicha o el muy importante sesgo que se asocia al género en estos grupos etáneos - donde hay una alta feminización del electorado- o una mezcla de ambas variables: edad y género lo que explique la cierta fidelidad política del electorado mayor (Sánchez Vera, Bódalo, 2000). Según datos de 1995, la población comprendida entre dieciocho y más años representaba el $13,8 \%$ de la población, que llevado al censo electoral representan el $20 \%$ de Ia fuerza electoral, y que como han puesto de relieve diferentes estudios, viene caracterizado por una baja abstención electoral (Justel, 1983: 186-203). Si algo puede ser destacado en España en los últimos años ha sido el aumento de la función protectora del Estado con respecto a los mayores. Para al gunos autores, este hecho, sin embargo, está realizado a costa de la presión fis- 
cal que se realiza sobre otros grupos, con lo que las políticas sociales no pueden estar reducidas a una parte sola de la sociedad sin tener consecuencias para el resto (Garrido, 1993).

Las organizaciones de pensionistas, así como sus encuentros, suelen estar presididos por un marcado carácter económico y/o reivindicativo. En el reciente C ongreso Estatal de Personas $M$ ayores, celebrado en $M$ adrid en febrero de 1998, en el que participaron representantes de los colectivos de la tercera edad, varias O N G y diversos colectivos de la Administración, estuvo presidido por un cierto debate sobre cuestiones económicas, y se trataron diferentes aspectos que van desde el futuro de las pensiones bajo el prisma del Pacto de Toledo, hasta la atención sociosanitaria de las personas mayores, haciéndose énfasis en los temas fiscales, proponiéndose, entre otros aspectos, los siguientes (conclusiones del grupo de trabajo 30 del I Congreso Estatal de Personas M ayores): 1. Disminución de la tributación de las pensiones. 2. M ejorar el tratamiento fiscal de las personas con ascendientes a su cargo. 3. La disminución de la presión fiscal indirecta para las pensiones de pequeña cuantía (hasta 100.000 pesetas) así como para los pequeños ahorradores. 4. Trato fiscal más ecuánime con respecto a las transmisiones patrimoniales, hoy competencia de las comunidades autónomas. D e otra parte, el proyecto de Ley de Reforma del Impuesto sobre la Renta (IRPF) de 1998 prevé, entre otras cosas, el hecho de que las familias que tengan en su casa, a su cargo, un anciano desgravarán más, así como que las pensiones más bajas tendrán una penalización. Esto ya lo había anunciado el IN SERSO tiempo atrás, la posibilidad de que las familias que tengan a su cuidado un anciano que no puede valerse por sí mismo podrán deducir unas cien mil pesetas. D e igual forma, el III C ongreso M undial de Amas de C asa, celebrado en junio de 1988, propuso que de los casi 6 millones de amas de casa españolas, que aportan el 18\% de la riqueza nacional, exigía, entre otras cosas, la posibilidad de acceder a fondos de pensiones específicos, esto es tener, derecho a cobrar una pensión de jubilación de la Seguridad Social (ABC: 24/06/98). En la actualidad, el Instituto de la M ujer está haciendo un estudio para conocer la aportación real de las mujeres al PIB.

\section{Empleo y jubilación}

Éstos son temas de especial trascendencia y en los que a buen seguro en los próximos años se seguirán desarrollando los estudios específicos al respecto. El empleo y la jubilación son factores íntimamente relacionados con el poder adquisitivo del sujeto, y el pase a la situación de jubilado - salvo situaciones muy excepcionales de jubilaciones incentivadas en las que el pase a esa situación supone unos ingresos adicionales importantes- supone una merma notable en los ingresos.

Como señala un especialista en la materia, hay que distinguir entre formas de trabajo y de actividad (Fernández Enguita, 1998: 56). Esta distinción se hace particularmente interesante en el caso de la mujer (p. 56) y de los 
mayores, donde las tareas domésticas suelen ser ignoradas de los análisis económicos, teniendo una importancia grande en el funcionamiento del sistema social y de la economía.

D esde la perspectiva de la actividad, uno de los casos más relevantes con que nos encontramos referido a los mayores es la reducción general de las tasas de actividad de los trabajadores de mayor edad - esto ocurre tanto en España como en la UE. Pero esa reducción no se ha limitado a los de más de 65 años. Se ha producido también en las edades anteriores, sobre todo entre los varones, lo que supone un notable acortamiento de la edad laboral. Las jubilaciones anticipadas parecen haber tenido una influencia relevante en este resultado. Este retroceso, registrado también en otros países, no sólo de la UE, ha venido a ampliar el colectivo de los «ancianos prematuros». Estos «ancianos» tienen entre 50 y 65 años. Como ponen de relieve distintos especialistas, los «trabajadores maduros» están sujetos a un concurso de circunstancias cada vez más complejas dentro del mundo laboral (Sempere N avarro, 1993). Entre 1987 y 1997, en España, la tasa de actividad masculina en el grupo de 60 a 64 años ha descendido en 15 puntos. Y en el grupo de 55 a 59 años, en 8 puntos. El impacto ha sido mucho menor en los correspondientes grupos de mujeres, ya que éstas tienen tasas de actividad muy inferiores a las de los hombres en esos grupos de edad. Según distintos estudios, en torno al $57 \%$ de los españoles se jubilan antes de los 65 años (G aviria, 1996: 97), cifra a todas luces desorbitada en el contexto europeo, pero que se ve claramente sesgada por las jubilaciones anticipadas acrecentadas con la reconversión industrial de finales de los años ochenta. Por tanto, nunca más que ahora, se está cumpliendo lo que muchos sociólogos han puesto de relieve al dividir la biografía de un sujeto en tres grandes etapas según el siguiente esquema: 25 años estudiando, 25 años trabajando y 25 años jubilado.

D e otra parte, fenómenos tales como la discriminación de los trabajadores europeos por motivos de edad, manifestándose en la poca disposición de los empleadores en contratar personas por encima de determinada edad (tal como ha puesto de relieve el informe elaborado en 1993 por Eurolink Age con motivo del Año Europeo de las Personas M ayores), empieza a hacerse sentir ya hacia los 45 años y se encuentra en su punto álgido a partir de los 50 a 55 años (D rury, 1993: 225). Este hecho, bastante extendido, pone de relieve que la mayor parte de los gastos que ha ocasionado a los presupuestos públicos el abandono anticipado de la actividad laboral ha tenido que ver poco con el envejecimiento demográfico. Y, de otra parte, lo que igual mente se ha puesto de manifiesto es que las jubilaciones anticipadas (salvo en muy raras ocasiones) no han sido el deseo de los trabajadores mayores, sino que ha sido más sufrido que querido.

Con todo, alguien ajeno al proceso español no entenderá como en torno al $57 \%$ de los jubilados lo hacen antes de los 65 años, pero aquí ha habido todo un proceso de reconversión industrial y la dinámica económica de diferentes sectores productivos que explican esta situación. D e tal suerte, el incremento del gasto en pensiones - en muchas ocasiones esgrimido como arma 
de un manifiesto catastrofismo del Estado del bienestar - puede inducir a error sobre la situación real de España. Como señala el profesor Fernández Enguita (1997) referido a los trabajadores mayores, «se trata de un grupo de personas cada vez más numeroso. Al que se reconoce plenamente su capacidad de trabajo, su derecho a ejercerla y la plenitud adulta de sus necesidades y deseos, pero que se ve estimulado o irremediablemente abocado al abandono de la vida activa 0 a una posición marginal en ella [... ] La jubilación anticipada es un fenómeno creciente entre los trabajadores adultos. Esta situación es vista frecuentemente como una salida digna por este trabajador, una vez que se van deteriorando las condiciones de trabajo». El anterior trabajo pone de relieve el incremento del subempleo en los trabajadores varones de edad avanzada que persisten en el mercado de trabajo. Estos trabajadores, sobre todo a partir de la edad de jubilación, tienen más posibilidades que otros grupos - más posibilidades que el resto de adultos, pero menos que los jóvenesde estar en la economía sumergida (Colino Sueiras, 1994). C on respecto a las actitudes hacia la jubilación, la última encuesta realizada en toda la U nión Europea sobre la edad deseable de jubilación (D e M iguel, 1997: 91 y s), daba los siguientes resultados: el $25 \%$ de los entrevistados deseaban jubilarse antes de los 65 años, al 25\% les parece bien la edad de 65 años para acceder a la jubilación, el 25\% desearía seguir trabajando después de cumplidos los 65 años, el 25\% no tenía una opinión decidida al respecto.

\section{Cuidado y atención al mayor}

Cuando hablamos de los mayores y la economía, es claro que hay que hablar de las formas de convivencia y de los niveles de autonomía funcional y psicológica de los mayores en relación con sus familias.

En España hay distintas estimaciones sobre el número real de ancianos que viven en residencias (no es fácil su contabilidad), oscilando dichas estimaciones entre el 2 y el $5 \%$ del total de ancianos. Según estimaciones oficiales, existen en la actualidad en torno a 2.500 centros residenciales privados y 660 públicos (con una ratio media de plazas muy superior a las privadas), con una oferta de más 80.000 plazas, un 2,9\% de la población mayor de 65 años. Q uedan fuera de dicha contabilidad muchas plazas de residencias privadas en situación paralegal, por lo que es difícil decir el número real de mayores en residencias. En cualquier caso, en el año 2005, el Plan Gerontológico prevé que el porcentaje de mayores en residencias esté en el 3,5\% del total de mayores de 65 años, lo que requiere una creación de más de 50.000 nuevas plazas en los próximos años.

En España, la residencia es considerada la última opción, cuando fallan las demás. Los demás viven en su hogar (aunque sean solos) o con su familia más o menos extensa, pero además incluso cuando están solos suelen estar bien comunicados, bien sea con sus parientes o con personas allegadas, lo que hace deducir que hay una red de relaciones económicas. Como han puesto de relieve diferentes estudios, es frecuente la proximidad residencial 
(vecindad) de los familiares con respecto a los padres, así como el hecho de que incluso en estas situaciones de soledad, hijas o nietos pasen parte del día con los mayores.

D e otra parte, la presencia de algún miembro de 65 o más años en el hogar, es más elevada cuanto mayor es el tamaño del hogar (D íez N icolás, 1997: 153), así, un 21,9\% de los hogares de 5 miembros, un 32,0\% de los hogares de 6 miembros y un 36,1\% de los hogares de más de 6 miembros tienen en su seno a algún mayor. Como señala Díez N icolás (o.c.), en cualquier caso, está reduciéndose el tamaño medio de los hogares, tanto por el crecimiento de los hogares unipersonales, como por la permanencia de los mayores con su pareja en sus hogares, así como por la gran disminución de la natalidad habida en España a partir de década de los ochenta. Así, aunque estén disminuyendo los hogares de 5 y más miembros, sin embargo, la presencia de un mayor número de miembros en un hogar no implica más hijos, sino mayor número de otras personas, en muchos casos progenitores de la pareja (D íaz N icolás, 0.C.: 153).

Un fenómeno en aumento en España (y en los países desarrollados) es el del gran crecimiento que han experimentado los hogares unipersonales 0 solitarios. En España se ha producido un gran crecimiento de los hogares solitarios constituidos por personas mayores (Sánchez Vera, 1996). Según los datos de la Encuesta Sociodemográfica del IN E (1993), el total de hogares unipersonales o solitarios existente en España era de 1.585.477 (un 13,40\%), si tenemos en cuenta que en el censo del 1981 estos hogares eran 1.085.078 (un 10,25\%), nos encontramos con que los hogares unipersonales han crecido entre 1981 y 1993 en 500.399 (un incremento del 3,15\%). Ahora bien, si desagregamos los datos de los hogares unipersonales existentes en España, nos encontraremos con que del total de hogares unipersonales, el $62,5 \%$ son personas mayores de 65 años. De ese $62,5 \%$ : el $47 \%$ son personas comprendidas entre 65 y 79 años y el $16 \%$ son personas mayores de 80 años de edad (0.C.: 69-70).

Este hecho es importante por cuanto denota una realidad social creciente: Ios viejos solitarios, que van a ser cada vez más demandantes de servicios asistenciales de todo tipo, al ser más vulnerables. Lo que va a hacer crecer (ya lo está haciendo) el sector de servicios para la tercera edad, con una gama amplia y diversificada de productos más o menos incardinada con los servicios sociales municipales o regionales o con varias O N G más o menos especializadas. Estos productos van desde empresas de tel ealarma y teleasistencia hasta los hogares asistidos y hogares de día, las empresas de asistencia domiciliaria, pasando por la previsible presencia de productos financieros específicos (planes y fondos de pensión) para la tercera edad para dar garantía y liquidez a los mayores que necesiten asistencia (o que sencillamente quieran llevar una vejez menos penosa económicamente), tales como la pensión a cambio de vivienda, Ilamado también hipoteca-pensión vitalicia (producto de cierto arraigo en países como el Reino Unido), o experiencias de solidaridad intergeneracional de diferente tipo, que están cubriendo también lagunas 
importantes del sistema público español de atención a los mayores, entre éstas se encuentran: el voluntariado que va a hacer compañía o sencillamente ayuda en tareas domésticas o en hacerle la compra o en supervisar el uso y el consumo de los medicamentos, etc. Algunas experiencias se han mostrado particularmente innovadoras y relativamente exitosas en al gunas universidades españolas, se trata de que, bajo la supervisión de expertos (trabajadores sociales generalmente), el mayor da alojamiento en su vivienda (de la que sue le ser propietario) a un estudiante de escasos recursos económicos, que con el compromiso de hacer una serie de tareas domésticas y de hacer compañía al anciano, le permite tener un alojamiento gratuito durante el tiempo de realización de sus estudios. Es previsible en los próximos años un crecimiento de las especialidades de la sanidad relacionadas con la atención geriátrica, así como el sector de los servicios relacionado con el cuidado de los mayores, y también con el ocio especializado y segmentado.

C on independencia de las opiniones más o menos favorables de la sociedad y del resto de la familia, el hecho de vivir con otra persona aporta al mayor más seguridad. D e esta forma, la mutua asistencia que se produce entre los mayores le da garantía y confianza. Cuando no es posible vivir con familiares o personas allegadas, el nuevo matrimonio es una salida. Las mejores posibilidades de encuentros entre mayores de diferente sexo fuera de su medio (viajes, vacaciones) o en los propios hogares o club (bailes, etc.), han favorecido las relaciones entre los mayores de diferente género (e igual estado: viudez generalmente). U na de las consecuencias de este hecho ha sido el alza experimentada en los matrimonios entre mayores (generalmente entre viudos), o sencillamente las parejas de hecho o uniones estables no matrimoniales, o en algún caso los matrimonios sólo canónicos para no perder la pensión de viudedad de su anterior matrimonio (generalmente viudas). Este es un asunto complejo, ya que es obligación de párroco notificar en el Registro Civil la celebración de estos matrimonios (nos referimos a matrimonios sólo canónicos), pudiendo ser un fraude ante el que la fiscalía o el fisco (ya que ante todo es un delito fiscal), podrían actuar de oficio, aunque en cualquier caso y sin que sea justificatorio, es un hecho relativamente excepcional, y el delito no suele ser grande, pues cuando ocurre se trata de viudos que cobran pequeñas pensiones. 0 tro aspecto interesante a considerar, desde el punto de vista de las familias de estos contrayentes, es el hecho de que los hijos suelen condicionar su anuencia al establecimiento de régimen de separación de bienes, mediante la consiguiente escritura de capitulaciones matrimoniales. En la actualidad se encuentra en trámite parlamentario un proyecto de ley que permitirá el matrimonio entre pensionistas sin que necesariamente tenga porqué implicar la pérdida de la pensión de viudedad y, a juicio de al gunos especialistas, tiene vinculaciones con el proyecto de ley de parejas de hecho, tal como ha hecho recientemente la Generalitat de Cataluña (Ley C atalana de 15 de julio. BO E 19-08-98), aunque dicha ley no contemple la situación jurídica de la pensión en el caso de parejas de hecho entre mayores. En cualquier caso, el matrimonio civil y/o canónico entre mayores es un 
asunto de extraordinario interés, pues los «impedimentos» contemplados por el derecho canónico sobre la validez de los matrimonios entre mayores, no encuentran su correspondencia en el derecho civil (López Alarcón, N avarro Vals, 1999: 103-108, 374-377).

0 tro aspecto a todas luces interesante, si lo vemos desde la óptica económica, es el del crecimiento del número de ancianos con cargas familiares. Aunque no tenemos muchas investigaciones al respecto, todo hace indicar que sobre algunos ancianos está recayendo una responsabilidad familiar importante que incluye, además del inevitable cuidado del cónyuge en caso de enfermedad o incapacidad, una buena parte del peso de la crianza de los nietos, y, de forma creciente, el cuidado de sus propios progenitores de muy avanzada edad. Según han puesto de relieve diferentes estudios, es creciente el número de mayores que tienen a sus padres o suegros a su cargo. Según revela la Encuesta Sociodemográfica de 1991, aproximadamente unas 539.000 personas con 60 y más años tienen aún padres vivos, y la cuarta parte de ellos viven en el mismo hogar.

El retraso en el abandono del hogar de los hijos (aún teniendo éstos trabajo), hace que muchas personas mayores alcancen la jubilación con las consabidas restricciones económicas teniendo algún hijo a su cargo. Este hecho es especialmente singular en el caso de España, teniendo en cuenta las elevadas tasas de desempleo existentes, así como las bajas tasas de nupcialidad juveniles y, sobre todo, el importante papel protector de la familia. Esto contribuye a que exista un creciente número de pensionistas que tengan cargas todavía de hijos que viven en casa y que no han despegado. Esta situación gozosa mientras está en activo el cabeza de familia, se convierte en penuria y en empobrecimiento cuando pasa a jubilado y ve mermar sus recursos económicos. Aunque la propiedad de la vivienda es mayoritaria entre los mayores. Un $75 \%$ habitan en vivienda de su propiedad que tienen pagada. Sin embargo, está por estudiarse la situación económica del grupo restante de mayores que viven en viviendas de alquiler, siendo interesante de conocerse con más detalle el impacto que han tenido sobre las pensiones de los mayores hechos como la Ley de Arrendamientos U rbanos de finales del año 1996 y sus consecuencias en las economías domésticas de los mayores que viven en régimen de alquiler, entre un $10 \%$ y un 15\% (M OPU, 1991).

Referido al retraso en el abandono del hogar familiar por parte de los hijos, y según un estudio elaborado por el prestigioso demógrafo del CSIC Juan Antonio Fernández Cordón (El País, 28/04/97), para un 60\% de los jóvenes españoles, de entre 25 y 30 años, tener trabajo no es una razón para despegar del hogar familiar (Fernández Cordón, 1997). Un hecho sin precedentes en el contexto de la UE. Según los datos de la subcomisión del Congreso que aprobó 13 recomendaciones dirigidas al gobierno para apoyar la familia, sólo un $19 \%$ de los jóvenes españoles ha conseguido vivir fuera del hogar, y de ese porcentaje, el $62 \%$ se independiza para casarse, el $10 \%$ porque dice necesitar autonomía, el $9 \%$ para estudiar fuera de la ciudad y el $9 \%$ se traslada a trabajar fuera de su residencia. Entre las razones esgrimidas, y junto al ya nom- 
brado paro juvenil, se citan las siguientes: la incertidumbre del actual mercado laboral con contratos laborales temporales centrados en los jóvenes, los salarios poco boyantes de los jóvenes, el pánico a independizarse y quedarse sin trabajo, el deseo de ahorrar, la existencia de una cultura muy patrimonialista que tiende a comprar la vivienda en lugar de alquilarla, así como los padres más permisivos y solidarios que no piden cuentas, y la propia comodidad que aporta el hogar paterno carente de conflictos importantes (Alberdi, 1999: 107-109).

Con respecto a las residencias de tercera edad, en España es previsible, como hemos señalado, un crecimiento en la oferta de residencias de diferente rango y tipo, que atiendan las demandas crecientes de un público cada vez más diverso y heterogéneo, tanto en su nivel de dependencia o necesidad como en su poder adquisitivo, tal como de hecho ha venido ocurriendo en los últimos años en España (Barenys, 1993: 125). Con todo, este sector se encuentra aún escasamente desarrollado a pesar de algunos tímidos intentos con cierta vinculación con el ocio, la salud y el turismo. Pero un elemento importante a considerar, es la importancia de los lazos familiares en España en la atención a los mayores (Alberdi, 0.C.: 319-346; Rodríguez, 1994). Como pone de relieve Amando de M iguel (1994: 29), los mayores en España están menos solos de lo que en un primer momento pueden aparentar datos como el gran número de hogares solitarios de mayores. Referido a las formas de convivencia, es conocido el crecimiento del número de hogares solitarios o individuales que se ha producido en España en los últimos años. C omo señala este autor (o.c.: 30), en contra de lo que normal mente se piensa, el español es poco dado a emigrar a pesar de que las décadas de los sesenta, setenta y ochenta hayan sido de importantes movimientos migratorios. $\mathrm{H}$ oy el fenómeno realmente importante es el de la migración de personas mayores que emigraron durante el auge de los años sesenta y que retornan a sus lugares de origen (C abré, 1993). D etrás del bajo interés por emigrar de los españoles, se encuentran, entre otras, las siguientes razones: 1. La importancia que en nuestra cultura se da a los lazos familiares. N umerosos estudios han analizado lo importante que es para los españoles el vivir próximo a familiares o parientes. Esta lealtad familiar es una de las constantes de la sociedad española, que en situaciones de crisis económica se nota aún más (López Pintor, 1987), para al gunos autores, la vitalidad de la familia explica incluso por qué los españoles nos asociamos menos que otros europeos. 2. La propiedad de la vivienda en España es otro factor que caracteriza a los españoles (en torno al $80 \%$ de las viviendas lo son en régimen de propiedad). Éste es un elemento de estabilidad social, que hace que la gente sea más conservadora a la hora de mudarse, puesto que supone un alto coste financiero. 3. La escasa movilidad laboral. A pesar de la tendencia al empleo eventual, paradójicamente, este hecho inhibe el traslado geográfico.

En la atención a los mayores, como hemos dicho, la familia es en España el pilar de dicha asistencia. En la actualidad en España, en torno al 87\% de los mayores que necesita atención la recibe de su familia. En España, un 
$34,1 \%$ del total de hogares españoles tiene algún anciano; un 52,9\% de los hogares tiene algún anciano y otro miembro; un $47 \%$ de los hogares están formados sólo por ancianos (D e M iguel, 1997). Según el informe de la sociedad española de 1996-97 (D e M iguel, 1997) publicado por la U niversidad Complutense, preguntada a una muestra urbana su opinión sobre cuál es el mejor sitio para una persona mayor que necesite de cuidados constantes, aunque no sea un enfermo grave: Aproximadamente el 50\% de los españoles piensa que el mejor sitio para un anciano con esas características es la casa de sus hijos o familiares. El 35\% opina que la persona mayor debe permanecer en su propia casa aunque necesite a alguien que la atienda todo el día. El 14\% dice que optaría por la residencia de ancianos. Según dos estudios realizados en 1996 y 1997 por el IN SERSO sobre la situación de las personas mayores en España, se pone de relieve que unos 1,5 millones de españoles mayores de 65 años (un 27,3\%), sobre un total de 5,5 millones, dependen del cuidado directo de sus familias para realizar alguna de las actividades esenciales de la vida cotidiana. Los dos informes anteriores también realzan que una gran parte de los españoles cree que el cuidado de los ancianos es obligación de los hijos, a pesar de que sólo un $24 \%$ se manifiesta convencido de que, en el futuro, el cuidado de las personas ancianas seguirá corriendo a cargo de los hijos. En la misma línea que los estudios anteriores, la Encuesta sobre apoyo a la Tercera Edad (CIS, 1993) ratifica la opinión mayoritaria de que el cuidado de los ancianos es obligación de los hijos. Las recientes medidas (Ley de IRPF de 1999) sobre exenciones fiscales a los hogares que tienen a su cargo personas mayores, tienden a favorecer esta red. Sin embargo, poco a poco va disminuyendo la proporción de ancianos que viven con sus hijos u otros familiares. Así, en el año 1989 estaban en esta situación en torno al $24 \%$ de las personas mayores de 65 años, y en 1996 este porcentaje bajó al $19 \%$, pero lo más importante sigue siendo el hecho de que entre un 70 y un $80 \%$ de los mayores de 65 años sigue viviendo en su domicilio.

Un factor importante a considerar es la herencia y su papel en la atención informal a los ancianos. El hecho de que la herencia sea un arma en poder del anciano, es puesto de relieve por muchos profesionales y trabajadores experimentados en el trato con mayores, que tienden a observar la existencia de una cierta relación causa-efecto entre cuidado y herencia. Según esto, muchos mayores preferirían no decidir el reparto de la herencia hasta los últimos días de su vida, y siempre en función de cual sea el trato dispensado por sus hijos, familiares o personas más allegadas, estando este asunto íntimamente relacionado con el reparto de la carga en el cuidado y con el lugar de residencia del mayor. Para algunos expertos (D e U ssel, 1998: 158-160; Rivas, Vara, 1989: 447-453), como consecuencia de las dificultades de los jóvenes para independizarse, se está produciendo un adelanto de la herencia, ya que en circunstancias normales ese trasvase de patrimonio a los hijos sólo se produciría tras el fallecimiento de uno de los cónjuges. Incluso se ha constatado la presencia de «herencias negativas», al apoyar los padres a los hijos y, ante «el descenso del valor de las pensiones, [... ] la descapitalización que hubie- 
ron de soportar para adelantar la transmisión del patrimonio, puede dejar a los padres a merced de la solidaridad filial» (0.c.: 451).

\section{Situación económica de los mayores}

La situación económica objetiva del mayor viene determinada muy principalmente por su poder adquisitivo. 0 tra cosa son los hábitos de consumo que tiene y la generosidad familiar más o menos mutua o más o menos recíproca, pero para entender esto último hay que tomar en consideración las relaciones del mayor con su familia.

Referido al caso español, M ario Gaviria (1996) pone en relación la economía monetaria con los aspectos no formales del cuidado a los mayores en los siguientes términos: «los pensionistas españoles, con una pensión media aproximadamente del $50 \%$ de la media de la U E, tienen otras ventajas, en casi un $90 \%$ tienen la casa pagada y en propiedad y sobre todo, a diferencia de la Europa fría, las abuelas y abuelos españoles son aquí más respetados, más queridos y mimados, y eso por tradición, por solidaridad entre generaciones [... ] Los cuidamos y nos ayudan, no porque necesitemos sus pensiones - que vienen muy bien - , sino porque así debe de ser» (Gaviria, 0.C.: 98). «L os pensionistas españoles son algo más de 7 millones, con pensiones medias más bajas en poder adquisitivo que las de sus coetáneos europeos, pero con la diferencia de que no están solos» (0.c.: 96) [... ] Referido a las diferencias generacionales entre nuestros actuales pensionistas y sus predecesores, señala: «Los pensionistas españoles son la primera generación que disfruta en España de los resultados del Estado de bienestar. De los 7 millones de pensionistas, la mitad son jubilados (50\%) y la otra mitad se reparten a partes iguales entre inválidos y viudas (25\%-25\%). Señala el profesor $\mathrm{G}$ aviria (0.C.: 98): «H ay en España más pensiones y pensionistas, con la pensión media más alta que nunca (aunque sigue siendo baja comparada con sus coetáneos europeos) [... ] Además las desigualdades entre las pensiones más altas y más bajas se han ido reduciendo. Las más bajas han ido creciendo más deprisa que las máximas, que han sido sometidas a un tope. Además el papel de las pensiones no contributivas ha paliado situaciones de necesidad notable».

Un elemento importante es la percepción social de la vejez, tanto por parte de la sociedad como por parte de los propios ancianos, y existiendo distintas realidades de vejez (H ernández Pedreño, 1998), sin embargo, también es cierto que, desde el punto de vista cronológico, se han observado importantes avances en el caso español. A este respecto, resultan interesantes las palabras de M ario G aviria, cuando con manifiesto optimismo, señala: «Vejez, viudedad e invalidez., que connotaban históricamente tristeza, pobreza, sufrimiento y lágrimas, denotan hoy abundancia austera, longevidad saludable y cierta felicidad no explícita ni explicitada. Son cada vez más y mejor avenidos, gente querida por sus familias y mimadas por los bancos y cajas de ahorro en busca de pasivo [... ] Trabajaron mucho, lucha- 
ron más, casi un millón de sus parientes y hermanos pagaron con sus vidas la Guerra Civil, pasaron hambre e hicieron la acumulación primitiva de capital» (0.c.: 96). Sin embargo, siguen existiendo importantes bolsas de pobreza en España en el gupo de personas mayores de 65 años (FOESSA, 1994; C asado, 1995).

Pero desde el punto de vista económico, hay un factor que en modo alguno debe pasar desapercibido: el papel de las pensiones en las economías domésticas. Como ponen de relieve diferentes investigadores (Pérez O rtiz, 1998) (Bazo, 1996), las pensiones de los mayores en España tienen una importante función económica complementaria para las familias. En algo más de un tercio de los hogares españoles entra una pensión de la Seguridad Social, casi 7 billones de pesetas al año, que desde los bancos y sobre todo desde las cajas circulan animando la economía española. (Gaviria, o.c.: 98). Sabemos igualmente que, en general, los abuel os son más permisivos y generosos con sus nietos de lo que son sus hijos, siendo espléndidos en sus regalos y ayudas en metálico para la compra de ropas y juguetes para los nietos (G rande Esteban, 1993: 87). Los nietos piden frecuentemente a los abuel os cosas y caprichos que no les dan los padres, aunque en al gunos casos existe cierta complicidad en el silencio anuente de los hijos. D e otra parte, la figura del abuelo, al igual que la del padre o de la madre, tendrá su día en el calendario comercial en los próximos años. En Estados U nidos ya se cel ebra desde hace años el «día del abuelo», y en España ya tímidamente se empezó a celebrar por primera vez el día 24 de julio de 1998 (aunque, indirectamente, también se rinde tributo al abuelo a través de los días del padre y de la madre).

Con todo, el poder adquisitivo sigue siendo la base del nivel y tipo de consumo que realizan los mayores, existiendo cierta heterogeneidad en los poderes adquisitivos, pero dominando todavía las rentas bajas (CIS, estudio núm. 2.072). Según el estudio del I N SER SO (1995: 163), en el que se preguntaba a una muestra de 2.500 entrevistados en todo el territorio nacional mayores de 65 años sobre qué tipo de ingresos propios tenían (él o su cónyuge ingresos propios), el ranking era el siguiente: el 57\% cobraba pensión de jubilación propia; el $25 \%$ lo hacía de su cónyuge; el 16,7\% cobraba pensión de viudedad; el 5,2\% cobraba pensión de invalidez propia; el 3,5\% cobrabas pensiones no contributivas o ayudas asistenciales; el 1,9\% cobraba pensión de invalidez de su cónyuge; el 1,5\% cobraba sueldo, salario, estaba todavía trabajando; el 1,5\% cobraba otras ayudas; el 1,4\% vivía de rentas (alquileres, tierras, intereses de capital), y el 0,3\% cobraba un sueldo o salario del cónyuge que trabajaba.

Tomando como referencia la anterior encuesta, y referidas a las tres principales fuentes de ingreso mencionadas (pensión de jubilación propia, del cónyuge y de viudedad), el género es una variable significativa, que juega en favor de los varones, pues si nos atenemos a los datos, nos encontramos con lo siguiente: 
Tabla 1.

Pensión jubilación propia

Varones

M ujeres

Pensión jubilación del cónyuge

$89,9 \%$

$33,5 \%$

Pensión de viudedad

$5,7 \%$

$38,8 \%$

Fuente: IN SERSO, 1995.

D e otra parte, el citado estudio del IN SERSO (1995: 164) pone de relieve lo parco de las pensiones de los mayores en España, situándose (fecha de realización de la encuesta: noviembre de 1993) un 60,4\% por debajo de las 65.000 pts. mes, y sólo un 9,6\% decían superar las 100.000 pts. al mes. Con independencia de la fiabilidad que estos datos puedan tener en una población que suele tirar a la baja sus ingresos, y sobre todo, los mismos son sólo una referencia sobre el poder adquisitivo y aún más sobre la calidad de vida, pues, tal como hemos señalado, tienen los grandes gastos realizados (vivienda equipada y en propiedad) e incluso algunos ahorros acumulados. Sin embargo, hay que insistir, una vez más, en la situación de pobreza relativa en la que viven los mayores en España. Es esa situación de pobreza objetiva la que lleva a contener el gasto al extremo. D iferentes estudios son coincidentes (incluso en el dato) en la preocupación real de los mayores en llegar a fin de mes. Así, en el ya citado estudio del IN SERSO (1995: 165) y a la pregunta «Con los ingresos totales de su hogar, llegan usted y su familia a finales de mes con mucha/bastante facilidad, con alguna/bastante/mucha dificultad», se observa que un $56,7 \%$ dice llegar con dificultad a finales de mes, a pesar de que el dato pueda relativizarse si lo desagregamos en las diferentes opciones: con alguna dificultad $(38,6 \%)$, con bastante dificultad $(12 \%)$, con mucha dificultad $(6,1 \%)$. M ientras que los que dicen llegar con facilidad representan el $41,5 \%$ que, desagregado, queda así: con mucha facilidad $(5,4 \%)$, con bastante facilidad $(36,1 \%)$. D atos muy similares a los del IN SERSO, salen en el estudio de Servando Cano referido al municipio de Gijón, donde a la pregunta «¿C ree que podrá cubrir sus necesidades económicas en el futuro?», un 55,9\% cree que no (Cano, 1990: 128); y en el estudio núm. 2.072 del Centro de Investigaciones Sociológicas (CIS, 1993).

En general hay que afirmar que existe una cierta percepción negativa sobre la situación económica. D icha situación Ileva a que aquilaten aún más su conducta económica y a que ahorren. El poseer ahorros da seguridad al mayor, tal como señalamos anteriormente. Un factor diferencial en los dos estudios referidos es el hecho de que la mujer aparece como más pesimista (CIS, 1993). En el estudio de Cano, un $61,7 \%$ de las mujeres frente a un $47,1 \%$ de los varones piensan que no podrán cubrir sus necesidades en el futuro (0.c.: 128). En el estudio del IN SERSO (0.c.: 165), las mujeres aparecen igualmente como menos optimistas (o más pesimistas si lo queremos así) que 
los varones en cuanto al grado de facilidad para llegar a fin de mes: mucha facilidad 7,5\% de varones frente a 3,9\% de mujeres; bastante facilidad $40 \%$ de varones frente a 33,3\% de mujeres. A la inversa, sobre la dificultad, las mujeres son claramente más pesimistas: con alguna dificultad $41,6 \%$ de mujeres frente a 34,5 de varones; con bastante dificultad 13,3\% de mujeres frente a $10,2 \%$ de varones).

\section{Los mayores y el consumo}

Tal como señalamos, los economistas prestan atención al mayor como consumidor - aunque no en correspondencia con el segmento real de población y de consumo que representan- y cuando lo hacen, lo es más como demandante de servicios públicos y como una parte creciente del gasto social. Sin embargo, el mayor como consumidor es relativamente poco conocido, a pesar de que represente un número creciente de consumidores: «A medida que crece el número de consumidores ancianos, aparecen preguntas nuevas sobre su importancia para las que no se posee experiencia en el pasado» (M oragas, 1991: 197).

El primer elemento a poner en juego referido al consumo es el poder adquisitivo, aunque no sea el único factor a considerar y menos en el caso de los mayores, donde estamos cansados de ver casos - que aunque sean excepcionales tienen altas dosis de simbolismo cultural - de mayores que viven en la mayor austeridad cuando no en la precariedad y que disponen de ingresos altos. En cualquier caso, es evidente que la jubilación, con la merma de ingresos mensuales que supone, impone una contracción en el consumo del mayor.

Como es bien sabido, el nivel de vida está articulado en base a procesos individuales y familiares, que se estructuran en torno al poder adquisitivo y a los hábitos de consumo. El mayor, ciertamente tiene unos hábitos de consumo relativamente arraigados, que podrían operar negativamente en su estructura de consumo al llegar a una nueva situación (la jubilación), en la que se produce una merma de poder adquisitivo. Sin embargo, el mayor cuenta en su haber con que tiene cierta experiencia en la administración de su poder adquisitivo. N adie como él suele objetivar e interiorizar su situación en términos de consumo con tanta dedicación y eficacia (fuerza obliga). D e una parte, ha pasado diferentes etapas de su vida en las que ha tenido que adecuar su consumo a las circunstancias individuales (ingresos) y familiares (ciclos de vida). D e otra, sus grandes necesidades suel en estar cubiertas, aunque lógicamente surgen otras nuevas (v.g.: asistencia sanitaria, servicios sociales), las cuales van a generar una demanda y gasto mayores del sistema público, lo cual está ligado a la mayor esperanza de vida (M oragas, 1991: 197).

Con todo, la población de mayores (sobre todo en España), aún teniendo rasgos diferenciales, tiene elementos cultural-generacionales comunes que sesgan y definen su cultura económica y que en consecuencia van a determinar su posición respecto al consumo. Estos rasgos vienen muy marcados por la cultura económica de la subsistencia, al ahorro en el sentido más tradicional 
(privaciones), y a la contracción y al control del gasto en todos sus capítulos, aun por encima de su poder adquisitivo real.

$\mathrm{N}$ o debemos olvidar un elemento subjetivo del consumo que es referido a los niveles y los hábitos de consumo contraídos, que hacen que el mayor, en principio, por el hecho de pasar a la situación de jubilado o a ser pensionista (por viudez, invalidez u otras circunstancias) tenga que adecuar sus hábitos de consumo a la nueva situación (económica o familiar). Es verdad que el hecho de tener unos hábitos adquiridos puede operar negativamente en la calidad de vida del anciano que debe moderar sus niveles de consumo y aquilatar el gasto hasta sus últimas consecuencias. Pero, como hemos señalado, también es verdad que el mayor tiene cierta experiencia en regular su consumo adecuándolo a su propio ciclo familiar y de consumo, pues ha pasado a lo largo de su vida por diferentes vicisitudes económicas, producto o consecuencia del juego de procesos objetivos y subjetivos. Lo que es evidente, es que la edad desde el punto de vista cronológico ( $y$ en tanto que suma acumulada y exponencial de experiencias), introduce factores objetivos, pero igualmente importante es el contenido o las características de las situaciones vividas y que le han hecho seguir procesos de maduración determinados, que en el caso del consumo suelen ser la racionalidad económica, el ahorro y la contención del consumo.

El consumo es, fundamentalmente, un fenómeno familiar, y es difícil conocer con detalle la estructura del gasto en las distintas fases del ciclo de la vida de un sujeto. D iferentes estudios han puesto de relieve como cada una de las etapas o ciclos de vida familiar del sujeto llevan emparejados una serie de gastos (Ruíz de M aya, 1994). C on todo, existe una ciertra horfandad de trabajos de investigación sobre el consumo familiar de los mayores en España. Según el estudio realizado en USA a finales de los ochenta para la compañía norteamericana J. Walter Thomson denominado Etapas de vida, donde se realizaron un importante número de entrevistas en profundidad y una encuesta a 2.100 familias basada en un cuestionario en el que se incluyen más de 150 variables: demográficas, de actitudes psicológicas, hábitos de consumo y utilización de marcas y productos (Alonso Rivas, 1997). Con independencia de que el citado estudio puede ser etnocentrista y los resultados difícilmente podrían ser extrapolados a España, donde el poder adquisitivo de los mayores es diferente, y también son diferentes los ciclos familiares, sin embargo puede resultar interesante. Según el estudio, se establecieron hasta nueve segmentos que corresponden a las diferentes etapas del ciclo familiar y los consumos básicos que se establecen en cada una de ellas. Éstos fueron los ciclos: Nido lleno 1 (matrimonios jóvenes con hijos menores de seis años): Productos para el hogar/Productos infantiles/energía, cal efacción/Servicios médicos/Escuelas. Nido lleno 2 (matrimonios jóvenes con hijos mayores de seis años): Colegios/Alimentación/Vestido y Calzado/N ueva vivien$\mathrm{da} / \mathrm{M}$ aterial deportivo/C réditos.

Ciertamente, muchos de los model os teóricos sobre comportamiento de los consumidores utilizados por el marketing, miran más los factores que 
impulsan a consumir un determinado producto y/o una marca concreta. Es por esto que algunos autores entiendan que ese tipo de literatura (referido al marketing) deba ser denominada como de «comportamiento de compra» y no como de «comportamiento del consumidor» (N avarro, 1987: 500-501), pues los aspectos sociales del consumo son básicos y nunca deben ser reducidos a la parte psicológica. Las implicaciones y el estatuto teórico del consumo suponen toda una relación social, tanto en la función como en la forma 0 «signo» del objeto de consumo (Pérez-Agote, 1978), y de otra parte, desde el punto de vista metodológico, la demanda de objetos de consumo está entreverada con model os sociales generales (O rtí, 1994), que no le son ajenos al consumidor mayor. Con respecto al consumo de las personas mayores en España, éste no podrá ser aislado de las diferentes características que tienen model os de consumo más globales y su evolución específica (Alonso, Conde, 1994; Conde, 1994).

Referido a las etapas en las que existen personas mayores dentro del hogar, las que siguen son las etapas del ciclo y los bienes y servicios de consumo más usuales en cada una de ellas: 1) En la fase de N ido lleno 3 (matrimonios maduros con hijos dependientes), los bienes más usualmente consumidos eran los siguientes: educación universitaria, segundo automóvil, mobiliario y hogar, libros y revistas, viajes. 2) En la fase de $\mathrm{Nido}$ vacío (matrimonios mayores sin hijos viviendo en casa): mejoras del hogar, viajes, planes de pensiones, productos de inversión, servicios médicos. 3) Sobreviviente (personas mayores que se han quedo solas): transporte, productos farmacéuticos, ocio y recreación, viajes, servicios domésticos.

A partir de los datos existentes en España (IN E), la clasificación por grupos poblacionales más parecida a la establecida por el comportamiento del consumidor, nos dice que los hogares formados por personas de más edad que suele coincidir con las fases de «nido vacío II (matrimonio sin hijos que convivan con ellos) «nido vacío III » (matrimonio con uno de los cónyuges jubilado), y supérstite solitario, gastan más que la media, en términos relativos en los grupos: $\mathrm{G} 1$ (alimentación, bebidas y tabaco), G 2 (vestido y calzado), G3 (vivienda, calefacción y alumbrado) y G5 (servicios médicos y gastos sanitarios). C omo ponen de relieve al gunos especialistas, «sería deseable una mayor profundización en el consumo de los hogares en los que viven mayores, aunque esta tarea no siempre es fácil, pues en la ECPF del INE los datos son por hogares y no por sujetos» (G rande Esteban, 1993: 31-32). En cualquier caso, si tomamos en consideración el gasto anual medio según la edad del sustentador principal para los ditintos grupos de gasto, tal como podemos apreciar en la tabla 2, referida a la Encuesta de presupuestos familiares (IN E, 1990-91), nos encontramos con que los hogares cuyo sustentador principal es un mayor de 65 años, gastan su dinero en mayor proporción que otros hogares en alimentación.

Uno de los fenómenos conocidos es, a diferencia de otros grupos de población (jóvenes), la existencia de un ocio no monetarizado por parte de los mayores, y esto a pesar de tener bastante tiempo libre. Tareas tales como 
Tabla 2. Gasto anual medio por hogar (\%) según edad del sustentador principal. España, 1990-91.

\begin{tabular}{lccccccccc}
\hline $\begin{array}{l}\text { Grupos } \\
\text { de edad }\end{array}$ & Alimentos & Vestido & Vivienda & Hogar & Salud & Transporte & /O cio & O tros \\
\hline $0-29$ & 23,1 & 10,5 & 10,5 & 6,5 & 3,2 & 17,4 & 7,4 & 21,3 \\
$30-44$ & 27,1 & 11,6 & 9,5 & 7,0 & 3,0 & 15,1 & 8,2 & 18,4 \\
$45-64$ & 27,9 & 11,2 & 9,4 & 5,9 & 2,9 & 14,8 & 7,3 & 20,5 \\
$65+$ & 34,6 & 10,7 & 13,6 & 6,9 & 3,5 & 8,9 & 4,3 & 17,4 \\
\hline
\end{tabular}

Fuente: Encuesta de presupuestos familiares, 1990-91. IN E.

ir al hogar del pensionista, pasear, tertulias y sobre todo televisión, mucha televisión, ocupan el tiempo del mayor (CIS, 1995).

La sociedad de consumo en España entró algo más tarde que en nuestros vecinos de la UE (Alonso, Conde, 1994), pero entró decididamente como consumo voraz y dependiente a partir de los años sesenta (C onde, 1994: 147148). El incremento en el poder adquisitivo, en el ahorro, en el crecimiento en el parque de automóviles (Sánchez Vera, Sánchez Galindo, 1995) y en la venta de productos relacionados con el cuidado del cuerpo y los equipamientos domésticos (teléfono, televisión), son algunos de los hechos más conocidos (C astillo C astillo, 1987: 54-60). Los mayores actuales - con grandes diferencias por subgrupos etáneos, hábitat y nivel económico- de alguna forma ya conocieron algo tarde el fenómeno del consumo de masas, con lo que en general no son un colectivo imbuido plenamente de la mentalidad consumista, de ahí que un cierto corte generacional deje a estos grupos etáneos alejados del consumo masivo e indiscriminado.

A modo de ejemplo vamos a hacer referencia al automóvil, como uno de los elementos más simbólicos de la sociedad del consumo. La implantación de la cultura del automóvil, se incorpora a España bien entrada la década de los años sesenta, que es cuando de manera progresi va se va incrementando el abanico de estratos sociales que tuvieron acceso al permiso de conducir como paso previo a la posesión de un automóvil, sobre todo de unas personas entonces en edades intermedias que por primera vez podían ser propietarios de un automóvil. A nadie se le escapa la masculinización cultural que tenía para aquella generación de españoles el acceso al permiso de conducir. Está por estudiarse en España, desde la perspectiva sociológica, el impacto que supuso en la sociedad española de entonces y de forma prioritaria para una generación - que entonces rondaba los cuarenta años y que hoy supera los setenta - la implantación del automóvil («revolución del utilitario») en tanto que proceso individual, familiar y social. El automóvil y su generalización como consumo familiar introduce distintos elementos de índole social: 1. Facilita la capacidad individual de desplazarse de manera autónoma y con libertad casi total. 2. Incrementa los contactos entre espacios (acercándolos), culturas y personas. 3. Introduce una nueva perspectiva: Ia del automovilista. 
4. Es una herramienta de trabajo, pero también es una continuidad del espacio familiar de la casa (casa rodante). 5. Intensifica las posibilidades de ocio, adquiriendo el automóvil y su conducción no sólo una dimensión de instrumentalidad, sino de fin en sí mismo (Sánchez Vera, Sánchez G alindo, 0.c.: 100). Un símbolo, pues, de la sociedad de consumo, como es el automovil, tuvo unos rasgos generacionales muy definidos, siendo cada vez más el número de conductores mayores (varones hegemónicamente en esas generaciones) que pretenden renovar su permiso de conducir, pues la posesión del coche les permite autonomía en los desplazamientos. El hecho de no poderlo renovar acarrea algunos costes importantes al mayor.

En cualquier caso, los mayores constituyen microsegmentos especializados caracterizados por una demanda diferenciada (Grande Esteban, 1993: 23). Uno de los sectores importantes es el mercado del ocio, particularmente si va unido a los viajes (y a la salud: balnearios, termalismo, etc.). El éxito de los programas de vacaciones del IN SER SO ha roto el esquema de quienes pensaban que a los mayores no les gustaba moverse. $\mathrm{H}$ a bastado el hecho de poner unos precios muy asequibles para que haya ido creciendo exponencialmente la demanda de plazas. Como ha puesto de relieve Anna Cabré (1993: 19), las generaciones que van a llegar a la jubilación van a ser cada vez más móviles, incluido el ocio, el turismo y la búsqueda de una jubilación «soleada».

U na de las características que más puede homogeneizar a los mayores es la disposición de tiempo para el consumo. Es por ello que gusta del trato personalizado y sosegado, no descartando el ir al punto de compra habitual como un lugar en el que comunicarse con otras personas. Con respecto a los hábitos de compra, el mayor dispone de tiempo, y el hecho de comprar, no sólo es una posibilidad de interacción social (con el comerciante o con otras personas, conocidas o no, que se encuentran en el mismo punto de venta), sino que también puede ser un entretenimiento. Así, el hecho de comprar es una «obligación» que ocupa, Ilena su tiempo y satisface al mayor. D e esta forma, el hecho de comprar los bienes de consumo no duradero, principalmente los productos alimenticios, es una obligación que suele ocupar un tiempo importante del mayor. En general, el consumidor mayor adquiere pequeñas cantidades y suele hacerlo a diario o con gran frecuencia mientras puede, a diferencia de sus hijos que tienden a almacenar productos y a comprar mensual o quincenalmente. Sabemos, igualmente, que los mayores pre fieren comprar por la mañana, evitando así las aglomeraciones, gustándoles más los pequeños establecimientos donde suelen recibir un trato más personalizado. De igual manera, hay más «fidelidad» en el consumidor mayor a un establecimiento determinado que entre otros sectores de la población.

Las grandes superficies (excepción hecha de aquéllas que se sitúan en el centro de las ciudades y tienen una atención individualizada), en general, no son una forma de compra atractiva para el mayor. D e una parte están distantes, y a ellas hay que ir en coche. Superada una primera fase de «curiosidad», la propia forma masiva de compra para personas que viven solas o con muy pocos miembros en la familia, no resulta práctica ni gratificante, salvo 
en el atractivo o atracción que podría suponer el precio más económico de algunos productos, pero el coste (desplazamiento, penalidades, etc.) es mayor que el beneficio. $\mathrm{N}$ i siquiera la forma de desplazarse por interminables pasillos con enormes carros entre gigantescos estantes, son formas agradables para la persona mayor, no estando previsto el hecho de poder sentarse a descansar. El sistema fabril, que impone la gran superficie, excluye al consumidor mayor. Ya que en la gran superficie el cliente es parte de la cadena de producción, ya que éste vacía los estantes (circulando con un pesado carro y seleccionando el producto que más le interesa), transporta los productos hasta la caja, donde debe empaquetar rápidamente porque viene empujando el siguiente cliente, y posteriormente hasta el coche. En la gran superficie todo es una cadena, pues los proveedores se hacen cargo del transporte de la mercancía, y la gran superficie sólo se encarga de ir reponiéndola.

Es verdad que el consumo, sobre todo en la gran superficie, está ligado al mercado monetarizado del ocio. Pero este tipo de ocio no suele satisfacer las necesidades del consumidor mayor, donde la comunicación es un valor primigenio. En suma, el consumidor mayor aporta una especie de resistencia ecológica a esta forma de consumo fabril que representa la gran superficie, aunque sólo sea por razones ligadas a sus necesidades de vida cotidiana. El consumidor mayor, a diferencia de otros consumidores, no actúa fácilmente ante el estímulo más o menos persuasivo como el perro de Paulov (que cuando ve el producto segrega saliva), pues no es un comprador compulsivo; de otra parte aquilata el precio y le gusta de seleccionar productos, si es posible que le sean conocidos y le infundan garantías. La utilización de productos de una misma marca, según diferentes estudios, es más frecuente en el consumidor mayor que en otros grupos de consumidores de menor edad. La fidelidad a una marca suele ser más alta en el consumidor mayor - que ha contraído hábitos de marca- que en otros grupos de consumidores de menor edad, y todo a pesar de tener un presupuesto muy limitado. En general el consumidor mayor es menos permeable a la innovación en el producto, pero si esa innovación viene de la mano de una marca en la que cree, es mejor recibido. En suma, una cierta fidelidad parece caracterizar la conducta de compra del mayor: en el establecimiento, en el tipo de producto y la marca del mismo.

El mayor no es uno de los grandes objetivos de consumo, partiéndose de la idea no siempre acertada de que dispone de escaso poder adquisitivo, pero va ganando poco a poco espacio y atención. En efecto, son mayoritarios los mayores con recursos escasos y que deben hacer un minucioso control del gasto para llegar a fin de mes, pero también es verdad que existen mayores que en términos reales poseen un poder adquisitivo igual o incluso más al to que el que disponen otros grupos más jóvenes, los cuales perciben unos ingresos sensiblemente superiores a los de los mayores. El hecho de tener una casa pagada y unos hábitos de consumo «controlados», es un capital adicional importante. Tampoco hay que desmerecer el hecho de que también algunos mayores cobran pensiones relativamente importantes, máxime teniendo en 
cuenta que en un alto porcentaje tienen su casa pagada. N o es extraño tampoco el que a la propia pensión (y la del cónyuge) tengan complementos provenientes de ahorro o de otras rentas. Sabemos - y lo saben sobre todo los bancos- del espíritu ahorrador de los mayores españoles. Espíritu ahorrador al que no es extraño el hecho de que tengan menos gastos fijos, hecho entreverado con el propio estilo de vida austero del mayor.

En general, y a pesar de la segmentación de los mercados, los mayores no han sido todavía abordados con la decisión que un sector tan importante de la población merecería. Los mayores constituirán a buen seguro un nicho de producción importante en los próximos años, donde existirán cada vez más productos especializados para ellos (al igual que los hay para niños, jóvenes, etc.) y que presten atención a la dieta necesaria del anciano que prevenga enfermedades como la osteoporosis y otras.

En efecto, las actitudes económicas de los mayores ante fenómenos como el consumo, vienen determinadas por diferentes variables, siendo sin duda las más sobresalientes las referidas a su situación económica (tipologías), su situación familiar y su salud. Pero también intervienen variables de corte subjetivo que están referidas a las propias actitudes vitales del mayor.

D iferentes estudios han puesto de relieve cómo a medida que avanzamos en el ciclo familiar disminuye el grado de decisión conjunta en el seno familiar, esto es que los matrimonios jóvenes toman sus decisiones más colectivamente, mientras que posteriormente la tendencia es a una mayor autonomía indiviudual (Ruíz de M aya, 1994). Una pregunta importante que ha de hacerse es, ¿quién decide el producto que se compra en aquellos hogares en los que el mayor convive con otros miembros de la familia? En general, y dentro de una gran diversidad de situaciones, y siempre que el mayor posea capacidades mentales suficientes, todo hace pensar que tiende a intervenir en el destino que se da a su dinero y, según algunos especialistas en la materia, incluso en el tipo de producto y marca que desea (Sara, 1993).

También será previsible el crecimiento de productos que faciliten la vida del mayor, y en donde la investigación y el desarrollo (I +D) de las empresas y de la administración prestarán mayor atención a la existencia y a la comercialización de productos ad hoc o relacionados con los mayores. El Viagra será un ejemplo de cómo se puede poner al servicio de la calidad de vida del mayor (y de otros sectores de población) los avances técnicos. Un asunto conocido, y al que el mercado no es ajeno, es el hecho de que los temas de salud interesan cada vez más a la población, pero el mayor muestra más interés por estos temas que los más jóvenes, particularmente en los asuntos de alimentación, donde el consumidor mayor debe llevar frecuentemente una dieta controlando, sobre todo, el colesterol, las grasas, la sal y el azúcar en las comidas. Los productos dietéticos, así como otros sectores (herboristerías) tienen entre sus clientes habituales a mayores. D e otra parte, y aún careciendo de estudios de mercado específicos sobre mayores, hay una serie de indicadores que denotan la utilización de ciertos canales de promoción y de distribución de productos específicos para el consumidor mayor (televentas, 
publirreportajes, viajes promocionales, etc.), siendo estos productos artículos relacionados con la salud o con el ocio, o con el menaje del hogar. Un asunto relacionado con el anterior, y que es denunciado por trabajadores sociales, personal especializado en tercera edad, asociaciones de pensionistas y/o de consumidores, es tanto la propaganda engañosa como el precio abusivo de muchos de estos productos. En general, y según se ha puesto de relieve en diferentes estudios, los mayores que son víctimas de abusos comerciales pertenecen a una generación de bajo nivel de instrucción y donde la cultura de la reclamación está poco extendida. En general, las estrategias comerciales dirigidas a los mayores suelen dirigirse a los sentimientos. LoS mayores, tanto por su cultura como sobre todo por su poder adquisitivo, no son compradores compulsivos, sin embargo sí que responden ante técnicas que apelan a la generosidad y al agradecimiento. Ese mismo sentimiento de agradecimiento es el que lleva - tras una excursión en la que se les han pagado el autobús y una frugal comida - a muchos jubilados a comprar cuberterías, mantas u otros objetos de dudosa calidad o que en los establecimientos comerciales resultan más baratos. El mismo sentimiento de generosidad es el que hace que abran la puerta a personas que venden a domicilio o que les venden participaciones en actos de solidaridad. En general, pues, los mensajes en los que el mayor es el comprador van dirigidos al corazón y a los buenos sentimientos. El mismo sentimiento de generosidad social, lleva a los mayores a ser igualmente proclives a dar limosnas y ayudas a necesitados.

En general, los productos pensados exclusivamente para personas mayores no suelen tener éxito, pues recordar la edad no es agradable. 0 tra cosa distinta son los productos destinados a disimularla. La disminución del tamaño de los envases de los productos de alimentación y limpieza como consecuencia de la disminución del tamaño de los hogares, habrá sido a buen seguro acogido con simpatía entre los mayores, pues con independencia del ahorro objetivo que puede devengarse del tamaño familiar del envase, sin embargo, se adecua a una dosificación y un escalonamiento del consumo más propicio para las personas mayores y que además evita el derroche que supondría el deterioro del producto.

En cualquier caso, sigue siendo un reto para los fabricantes españoles tener en cuenta a los consumidores mayores, no sólo ya en sus gustos y preferencias, sino también en el diseño de los productos y envases. Los botes cerrados al vacío, algunos cierres de envases, las minúsculas letras de determinados productos o de las propias recetas de los fármacos, no están pensadas para las personas mayores. D iferentes estudios han puesto de relieve la poca atención prestada por los consumidores mayores al etiquetado de productos, y no sólo eso, sino también la mala disposición de las etiquetas y la dificultad de lectura para personas con deficiencias de visión. Así, el exceso de información, la mala disposición de ésta y la incomprensión de algunos de sus contenidos, hacen que las etiquetas sean, en términos generales, rechazadas por los consumidores mayores en una mayor proporción que el resto de consumidores (VV.AA., 1994). 
En general, se puede afirmar que, salvo en contadas ocasiones, las empresas no prestan demasiado interés a los procesos de compra y a los mecanismos de comportamiento del consumidor mayor, incluso dentro de la extensa producción sobre marketing, ésta suele ser mínima cuando se trata del consumidor mayor. En cualquier caso, sí es conocido desde el punto de vista del consumo, y según los especialistas (G rande Esteban, 1993: 52), que uno de los elementos más valorados por el mayor a la hora de adquirir un producto es el precio. Este hecho no está reñido con una cierta tendencia del consumidor mayor a la fidelidad a un producto (0.C.: 84), ya que los hábitos de consumo del mayor están más arraigados que los del consumidor más joven, mostrando el consumidor mayor menos interés por probar nuevos productos (probablemente porque son menos propensos a la innovación, y por tanto a asumir riesgos), siendo de esta manera más difícil la introducción de un nuevo producto en el consumidor mayor, aunque, claro está, existen diferencias importantes según poderes adquisitivos y niveles y modelos culturales. Entre los temas que más interesan al consumidor mayor están el precio y el conocimiento del producto. 0 tro aspecto conocido entre especialistas es el hecho de que los consumidores mayores son relativamente reacios al pago aplazado. D e igual manera, son poco propicios a la utilización de la tarjeta de crédito. $\mathrm{N}$ i que decir tiene que estos hábitos en las generaciones futuras de mayores van a ir cambiando (ya lo está haciendo) poco a poco.

\section{Los mayores, la cultura económica y el ahorro}

La interiorización de la cultura económica, en tanto que «conjunto de valores, costumbres, modos de operar, conocimientos y orientaciones que dirigen la conducta de los individuos de una sociedad en los asuntos relacionados con la economía» (N avarro, 1992: 777), es un fenómeno que tiene un claro corte generacional. Estando también condicionado por el estatus del anciano, esto es, por factores tales como sus niveles de renta e instrucción, así como por su situación familiar. Como pone de relieve un experto en el consumidor mayor: «existe una relación directa entre el nivel de renta y el cultural y la predisposición a aceptar nuevos productos y servicios» (Grande Esteban, 1999: 54). La socialización de las generaciones más jóvenes con la cultura del consumo y de la imagen, el mayor nivel de instrucción de las mismas, así como el mayor nivel de integración en aspectos relevantes de la modernidad de la que la cultura económica es componente fundamental, alejan en cierta medida a los mayores de la cultura económica, introduciendo elementos de segregación social. En opinión de un experto: «H abría que analizar hasta qué punto, sectores de la población relacionados con las actividades primarias y trabajadores, generalmente poco cualificados, de la industria y los servicios, han sido escasamente permeables a la cultura económica. H ay detrás un claro corte generacional. Los jóvenes se han socializado en este medio cultural, simplemente por hacer nacido cuando tal cultura estaba ya difundida en toda la sociedad. M ás que la propia familia, los medios de comuni- 
cación, la práctica del consumo, las relaciones laborales y otras actividades económicas están siendo los agentes socializadores fundamentales, de tal modo que su modo de pensar se orienta predominantemente hacia los valores culturales descritos, que han sido asumidos sociológicamente, si bien con diferentes grados de intensidad, conformidad y/o rechazo. Por eso la marginación más extrema se produce entre las generaciones de mayor edad, los grupos sociales más distantes de la cultura predominante y/o aquéllos que se han visto desplazados por el sistema educativo, por sus cualidades físicas o psíquicas - y en general por su incapacidad para competir- o por el enfrentamiento cultural y la automarginación (N avarro, 1992: 786).

Referido al ahorro de los mayores, diferentes estudios han puesto de relieve la importancia del pensionista como cliente tradicional de las cajas de ahorro. Estas entidades financieras tienen un notable protagonismo dentro del sistema bancario español en relación con la media europea, ya que representan en torno al 50\% del mismo (Arancibia, 1998). Estas entidades surgieron para fomentar el ahorro entre las capas medias y ayudar al desarrollo regional, y han tenido entre sus clientes habituales a los pensionistas, lo que ha sido deseado por el resto de la banca, que se ha dirigido a la búsqueda del cliente jubilado, intentando arrebatar a la CECA (Confederación Española de $C$ ajas de Ahorro) una parte de este pastel (o.C.).

Entre las características que buscan y más valoran los mayores de las entidades financieras, están las siguientes:

1. La confianza (con los años ganamos en desconfianza y buscamos a quien nos la dé).

2. La seguridad (la inseguridad que van dando los años hay que amortiguarla con la seguridad económica y de una entidad solvente).

3. La calidad de vida.

La pregunta que se hacen las entidades bancarias es si cumplen los requisitos anteriores y si están dando respuesta a las características anteriores que se corresponden con la demanda de los mayores, así como si tienen unos productos y unos servicios adecuados a los mayores.

D e otra parte, las generalizaciones tampoco son adecuadas. Es verdad que hay unas inercias familiares que determinan al cliente mayor de las instituciones fuinancieras, pero no es menos cierto que ese es un parámetro más entre otros muchos, pues existen subsegmentos muy diferenciados. Así, en España, existen ocho millones de pensionistas. Esas pensiones cuestan 8 billones de pesetas al año, dinero que puede ser gastado 0 ahorrado.

Los mayores de 50 años son un tercio de los clientes de la CECA, representando el $50 \%$ de todo el negocio, ya que, como hemos señalado, a partir de esa edad están los patrimonios más saneados.

C omo hemos señalado, la fidelidad es uno de los factores que más van a caracterizar al consumidor mayor. También esta fidelidad se da con respecto a la entidad financiera en la que cobran su pensión y en la que depositan 
sus ahorros o inversiones. Este valor de fidelidad ha sido particularmente bien entendido por la CECA (a través de sus 46 cajas confederadas) que cuida y mima tradicionalmente a este segmento de clientes. En la actualidad, en España, en torno al $43 \%$ de las personas que tienen una pensión, la tienen en una caja de ahorro, el $47 \%$ en los cinco grandes bancos y el $10 \%$ restante en otras entidades bancarias.

La obra social ha sido una forma de intervención tradicional y eficaz por parte de las cajas de ahorro españolas para introducirse en el mundo de los mayores. La obra social gastó en el último ejercicio en torno a 105 mil millones de pesetas, realizando multitud de actividades dirigidas a los mayores de 65 años. Existiendo 1.076 centros destinados a la atención de las personas mayores de 65 años.

$\mathrm{H}$ ay diversos estudios realizados por la CECA sobre qué es lo que valoran más las personas de más de 55 años de bancos y cajas de ahorro. D e las cajas de ahorro lo que más se valora son sus actividades sociales y culturales, y, en segundo lugar, la atención que dan a la familia y la proximidad física. D e los bancos se valora el hecho de que den un interés superior.

Las cajas, desde su obra social y con su enraizamiento territorial, han tenido hilo directo con los pensionistas, y forman parte de la cultura económica de los jubilados.

El mercado bancario, con multitud de productos financieros adecuados para los mayores, ha entrado de lleno en la competitividad en este segmento de clientes que ofrecen ventajas a quienes perciban la pensión por esa entidad. También, la puesta en disposición de tarjetas para las personas mayores es un fenómeno en crecimiento en España. I gualmente, empresas públicas de transporte urbano, u otras como I beria, REN FE, Telefónica o Transmediterránea, ofrecen tarjetas y productos en condiciones ventajosas para el cliente mayor de 65 años.

Se sabe igualmente (G rande Esteban, 1993: 85) que las personas mayores son propensas por razones psicológicas al ahorro. La seguridad que éste reporta, así como una concepción relativamente tradicional del mismo (privaciones), han formado parte de la cultura tradicional de los mayores en España.

Referido al ahorro, los mayores en general se suelen mostrar conservadores - salvo en situaciones de patrimonios holgados- , siendo generalmente reacios a no tener liquidez, pues existe el miedo a sufrir al guna eventualidad 0 incluso a quedarse sin pensión, y no poder disponer en un momento determinado de sus ahorros (Grande Esteban, 1999: 60). En el caso del ahorro, suelen ser las posiciones más conservadoras desde el punto de vista financiero (Plazo Fijo, Tesoro) las que suelen gozar de las simpatías del cliente mayor, y aún así con las reticencias antes referidas. D e igual manera, los mayores no suelen formar parte del grupo de solicitantes de préstamos, y de hacerlo suele ser por circunstancias excepcionales, por escasa cantidad y en condiciones de amortización muy aquilatadas.

Pero, a pesar de lo antes señalado, los mayores en España tienen cada vez más cultura financiera, así como actitudes más activas hacia el mercado finan- 
ciero, que es lo mismo que decir que hay un menor progreso del ahorro tradicional entre los mayores, que tienen mayor cultura financiera y también - por qué no decirlo - actúan con mayor propensión al consumo, bien sea éste para repartirlo de manera generosa entre sus personas más allegadas (hijos y nietos generalmente) o simplemente en ellos mismos en una diversidad de productos que mejoran su calidad de vida (viajes, equipamientos domésticos, etc.). En este sentido, ciertos estudios de entidades financieras han detectado también un crecimiento en la demanda de créditos por parte de clientes mayores jubilados (un fenómeno relativamente excepcional). Bien es cierto que la rebaja en los tipos de interés ha favorecido este hecho, pero no es menos cierto que también han ido ganando espacio la cultura financiera y las actitudes consumistas entre los mayores.

0 tro de los temas que ocupan frecuentemente las conversaciones entre mayores, junto al de la pensión y salud, es el de la autonomía y el destino del dinero y del patrimonio (por poco que éste sea). Las conversaciones en torno al destino de la herencia o a su formalización en términos de testamento, etc., son algunos de los temas que también conforman la subcultura económica del mayor. La creciente presencia de espacios comunicacionales entre mayores, autónomos del núcleo familiar, no sólo divulgan algunos conocimientos económicos, sino también y lo que es más importante: actitudes y valores que refuerzan el autoconcepto y la autonomía que el mayor tiene en la administración de su patrimonio. Un hecho al que habrá que prestar más atención en España en los próximos años es al de las uniones y matrimonios entre pensionistas, que con frecuencia chocan con el recelo de los hijos, que desean hacer valer su situación de herederos antes de tolerar la conducta de su padre o madre.

En cualquier caso, sabemos que el tener dinero para el mayor es un hecho cargado de simbolismo. Pues no sólo lo ha trabajado y sabe mejor que nadie de lo que cuesta ganarlo y aún más ahorrarlo (a base de privaciones), sino lo que es más importante, el dinero reporta seguridad al mayor, pues, entre otras cosas, la eventualidad de caer enfermo y de necesitar a alguien que lo cuide y atienda necesita tener autonomía financiera. N o olvidemos que el sentimiento de tener seguridad es la principal preocupación del mayor. Las carencias y penurias a las que han estado sometidos los mayores en España les hace buenos administradores de sus economías domésticas, lo cual - no nos engañemos- es un valor capital de la cultura económica: el mirar la peseta.

El hecho del trato individualizado es un hecho de suma importancia para el mayor. En los bancos (sobre todo en las cajas de ahorro, donde depositan de forma masiva sus pensiones y ahorros los mayores españoles) seria deseable un trato más personalizado para el mayor, que gusta de pasar por la oficina. Es verdad que los bancos (con un perfil de cliente mayor, con alguna mayor formación que el pensionista cliente tipo de la CECA y de las cajas rurales han conseguido introducir la tarjeta de crédito entre los mayores, pero desde luego sin los éxitos que han tenido entre otros segmentos de la población. 
Lo que parece evidente, en cualquier caso, es el hecho de que el mayor tiene que aquilatar su gasto al extremo, pues ha de administrar con rigor su magra pensión. D e otra parte, dispone de tiempo sobrado para dotar de la máxima racionalidad económica a su conducta de consumo. Y por último, y a pesar de lo exiguo de las pensiones españolas y del pesimismo económico que determina el comportamiento del mayor, la toma de referencia con periodos anteriores de su propia situación económica en tanto que pensionista (no olvidemos la favorable evolución de las pensiones en España en los últimos diez años) y aún más la toma de referencia con respecto a generaciones predecesoras en la jubilación que pasaron todas las penurias, es un hecho relevante.

Sin embargo, y de manera paradójica, el mayor tiene que asumir y asume «o económico» como uno de los contenidos y de los significados más afianzados en su cotidianeidad. D e una parte, los temas de conversación frecuentes entre los mayores están referidos al dinero y a la administración de su economía doméstica, sin embargo están expropiados de ciertos conocimientos instrumentales imprescindibles. El bajo nivel de instrucción de los mayores los hace frecuentemente desconfiados hacia las mudanzas que la vida económica moderna impone.

También hay que observar que la mejora en la «cultura económica» de los españoles ha afectado extraordinariamente a los mayores. Un buen número de depósitos de ahorro a plazo proveniente de mayores, se ha convertido en fondos de inversión. La disponibilidad de tiempo y el intercambio de opiniones entre los mayores en uno de sus temas preferidos hace previsible un crecimiento de esta cultura económica. Algunos mayores con ahorros han hecho su incursión en los mercados bursátiles bien directamente o a través de fondos de inversión, siguiendo los consejos de sus hijos o de los delegados de su oficina en los que confían. $\mathrm{N}$ i que decir tiene que la caída de la rentabilidad de las imposiciones a plazo fijo (forma tradicional de ahorro del mayor), ha tenido mucho que ver con esto. Pero, en cualquier caso, todo hace indicar que no es un cliente emprendedor y mucho menos aventurero. Referido al ahorro de los mayores, señala M oragas (M oragas, 1991: 196-197) lo siguiente: «El Estado reconoce la importancia de las decisiones presentes de los futuros jubilados y trata de fomentar el ahorro, con lo que aumenta el capital disponible para inversión, detrae dinero del consumo y controla la inflación [... ], aunque [... ] el propio ahorro se ve afectado por la inflacción que devalúa en pocos años las pesetas ahorradas [... ] debido a ello, la población puede preferir el consumo presente al ahorro y futura renta empobrecida, olvidando la previsión del futuro en aras del bienestar actual».

Tal como hemos señalado, la cultura del ahorro es uno de los ejes centrales de cultura económica del anciano. Ya lo hemos dicho, el mayor, a pesar de su parca pensión, tiende a gastar lo imprescindible y aún menos, el resto lo ahorra o lo reparte entre sus familiares más allegados con los cuales convive o no, ya hemos hablado del papel de la pensión de los abuelos en el mantenimiento de muchos hogares españoles. Este factor es en el que hay que 
insistir, sin que por ello tengamos que restar vitalidad al papel asistencial de la familia en España. En palabras de un experto «os dineros de los abuelos, en general, son dineros bien administrados por una generación sobria, parca, que ahorra en sus libretas, para luego financiar juguetes a los nietos peque ños, entradas a la compra del piso para los nietos y que tapan los agujeros de fin de mes de sus hijos [... ] Es una generación que consume poco, y productos españoles, apagan la luz al salir, guardan las bolsas de plástico y las cuerdas y cintas de la tarta de cumpleaños. La gran función de las pensiones de la SS es la redistribución económica y social. [... ] los abuelos y abuelas españolas, con su consumo ordenado, son una demanda que genera desarrollo y, sobre todo estabilidad económica. Son además un pacificador social, una memoria oral histórica (en el seno de la familia) que nos recuerda permanentemente de donde venimos (un país pobre)». (G aviria, 1996: 98).

Ciertos elementos relacionados con la cultura del ahorro, como son las actitudes del mayor hacia la «reutilización» (sobre todo), la «recuperación» y el «reciclaje» de ciertos productos de su vida cotidiana, son de al guna forma elementos centrales de una cultura económica contraria al consumismo y al despilfarro, que a su vez forman parte del paradigma ecológico. Un reciente estudio realizado por la Comunidad de M adrid ha puesto de relieve una manifiesta colaboración de las personas mayores en las tareas de discriminación de papeles y vidrios. C on independencia de las anteriores conductas tipicamente cívicas y ecológicas, tambien el mayor se familiariza con ciertas actividades de reparación y bricolaje, muchas de las cuales están ligadas a la estrechez económica con que tiene o debe, o simplemente desea conducirse, y que le lleva por ejemplo a no llamar a operarios para pequeñas reparaciones domésticas. La disposición de tiempo libre le permite igualmente realizar de grado estas tareas domésticas y pequeñas reparaciones. Estas conductas son tanto masculinas como femeninas, aunque suelen ser más masculinas. La mujer, al quedar viuda, también tiene que realizar frecuentemente actividades domésticas a las que no estaba habituada, y puede mostrar un compartamiento más dependiente que el varón en la realización de las mismas.

Con independencia de que el mayor todavía es un sector poco relevante en el mercado (al menos en España), es creciente la existencia de productos especializados para las personas mayores, así cómo las ofertas que se dirigen a este segmento de consumidores, lo que nos permite hablar de una mayor preocupación (más o menos interesada, que es lo de menos en este momento).

La existencia de productos financieros especializados, la competitividad del mercado bancario de los últimos años en España (en gran parte disputándose al cliente pensionista), la existencia de una oferta de bienes y servicios más económicos y de descuentos especiales para el mayor, introducen posibilidades adicionales de las que el mayor puede acceder y disfrutar. El conocimiento y la divulgación del uso de estas posibilidades entre personas de su misma condición de jubilado (tarjetas azules, doradas, bonos transporte, descuentos para espectáculos, etc.), así como la transferencia de información 
sobre la rentabilidad y las ofertas que hacen las distintas entidades bancarias (cajas sobre todo) para los mayores que tienen domiciliada la pensión (adelanto, sorteos, viajes, puntos, etc.), forman parte, junto al ahorro como hecho capital, de lo que podríamos llamar una particular subcultura económica del mayor. Algunas investigaciones insisten en la importancia que tiene la relación personal que se establece entre el pensionista y el empleado de las entidades bancarias o cajas de ahorro, en las que los mayores depositan su confianza y atienden sus consejos en la toma de decisiones económicas. Esta situación de influencia suele producirse con mayor frecuencia con las personas mayores (sobre todo con aquéllas que viven solas o no tienen familiares próximos) que con otros colectivos.

La divulgación de los conocimientos sobre planes y fondos de pensiones entre trabajadores mayores e incluso entre los propios pensionistas, que por razones fiscales se interesan por algunos de estos productos adecuados a sus intereses, forman igualmente parte de la cultura económica. En este caso, podríamos decir que la cultura económica incorpora cada vez más conocimientos económicos relacionados con la jubilación - aunque no exclusivamente pues tiene otros incentivos: rentabilidad, fiscalidad, ahorro- como parte de sus conocimientos, costumbres, valores y modos de operar que dirigen la conducta de los individuos en una sociedad en los asuntos relacionados con la economía (N avarro, 1992 o.c.). O tros autores Ilaman la atención sobre la incidencia de los mercados financieros en los problemas vinculados a la jubilación y a la rentabilidad económica de las inversiones ligadas a la misma (Péne, 1999: 92-100).

En cierta forma, se podría decir que al gunos de los hechos centrales que constituyen los valores y la conducta económica del anciano, tales como el ahorro, la austeridad, el desdén al consumismo, la racionalidad en las decisiones, etc., constituyen la quintaesencia de la cultura económica. Aunque nuevas concepciones sobre el ahorro estén relativizando la idoneidad del ahorro-privación a favor del ahorro-inversión.

\section{La economía, los mayores y el género}

Las diferencias económicas por género han quedado patentes anteriormente. D entro del matrimonio, el estatus de cada cónyuge está ligado inevitablemente al estatus económico que tiene cada uno en función de los ingresos que aporta. En las actuales generaciones de mayores, el nivel de dependencia económico de la mujer es muy elevado (lo será menor progresivamente), teniendo en cuenta las bajas tasas de ocupación femenina de aquellas generaciones en sus edades activas. Tambien es verdad que hay model os culturales donde la mujer es la que repartía y administraba el destino del dinero que religiosamente le entregaba el marido. Pero, en cuaquier caso, las decisiones económicas han estado muy masculinizadas en las generaciones de los mayores actuales. Correspondiendo a la mujer un papel secundario en las grandes decisiones económicas, aunque en las pequeñas decisio- 
nes de gasto y compra la mujer ha tenido un papel preeminente. Sin embargo, en lo concerniente a temas tales como la gestión del ahorro, éste ha estado bastante masculinizado. D e tal suerte es esto así que, frecuentemente, la mujer no se ha preocupado por el destino y la gestión de sus ahorros (de tenerlos) hasta que son viudas. El cambio de situación personal y familiar que supone la mudanza de estado civil genera una serie de actitudes en la mujer particularmente interesantes, tal como han puesto de relieve diferentes estudios (v.g.: Inés Alberdi para España, o $O$ ctavio U ña y José M a Bleda en CastillaLa $M$ ancha). La viudedad es verdad que frecuentemente conlleva una pérdida de poder adquisitivo por parte de la mujer, pero tampoco hay que perder de vista el hecho de poder tener acceso y control de su patrimonio, situación que no siempre era posible, en un medio (el económico-bancario: cuentas) muy masculinizado. Tampoco se trataba del dinero que tenían - que podía ser más o menos-, sino de la posibilidad real y objetiva de poder decidir sobre el mismo.

En términos generales, la viudedad de la mujer implica cada vez más una situación de mayor independencia (antes la tenía respecto al marido). En el terreno económico, este cambio de situación hace que la mujer se tenga que reciclar en algunas cuestiones económicas. Si bien es cierto que la administración de la economía doméstica ha estado generalmente depositada en manos de la mujer, sin embargo al quedar viuda tiene que ir tomando una serie de decisiones que requieren al gunos conocimientos técnicos (por elementales que éstos sean) o incluso algún nivel de relación, pero todo hace indicar que en general aprenden con bastante rapidez. Según la información obtenida a través de entrevistar a diferentes testigos privilegiados de este hecho - como son los delegados de oficinas bancarias - tras la viudez, la mujer pasa un muy corto espacio de tiempo en el que se mueve con cierto temor, pues no entiende muy bien la gestión económica, pero transcurrido éste aprende con gran rapidez. E incluso, lo que es más importante, tras la situación de viudedad, con frecuencia, la mujer mayor siente la sensación de poder y de libertad con respecto al dinero, al haber estado la decisión económica (sobre todo en las generaciones más maduras de viudas mayores) en manos del varón. Volviendo al testimonio de al gunos de los testigos antes citados, las mujeres se quejan ante ellos de las penurias con las que tenían que llegar a fin de mes, pues era el varón quien solía marcar la cantidad de dinero disponible. Las anteriores quejas Ilevan incluidas frecuentemente alusiones a «que no las sacaba de casa, (referido al marido) mientras que él se iba a todos lados», o incluso que «tenían dinero ahorrado pero no le dejaban hacer uso de él». Se da la circunstancia en determinados medios (relatan los testigos) de que la mujer desconocía incluso el dinero del que disponían ahorrado sus maridos.

También, se da la circunstancia, en algunos casos, de que la mujer mayor viuda se deje asesorar por parte de los hijos, que con frecuencia «intervienen» en la gestión del patrimonio y de las libretas. Si algo falta a los mayores españoles a diferencia de sus homólogos europeos es autonomía y liber- 
tad en la gestión de su patrimonio. Sería deseable una mayor autonomía de nuestros mayores y una cierta «desvinculación» simbólica de sus hijos, que les permitiera vivir con un mayor grado de autonomía en todos los ámbitos de su vida, incluidos, claro está (y siempre que esto fuera posible) en el terreno del uso de su dinero, esto es, en las decisiones económicas. En cualquier caso, y aún no interviniendo directamente, sí que hay una preocupación - que suele ser recíproca (madre e hijos) - de aparecer en todas las libretas y cuentas de la madre. Sin embargo, referido a la autonomía de la mujer mayor viuda - también en opinión de los testigos- poco a poco se va observando una mayor autonomía en el poder decisional de su patrimonio y de su dinero. D eben concurrir en esta circunstancia variables generacionales, pero también otras referidas al cambio social y a los efectos que la cultura económica ejerce en la sociedad toda. Incluso se da la circunstancia de que a algunos testigos sorprende la audacia con que algunas mujeres mayores se dirigen en el terreno de la toma de decisiones económicas una vez que se han visto desligadas de ciertas ataduras conyugales (Sánchez Vera, Sánchez-M ora, 1998).

\section{Los mayores y el juego}

0 tro hecho que llama poderosamente la atención en la cultura cotidiana del mayor es la afición al juego de azar. Como ya han puesto de relieve diferentes estudios (v. g.: REIS 1989, D atos de 0 pinión: 291-312), la lotería (sobre todo de $\mathrm{N}$ avidad) y otros juegos de azar encuentran entre los mayores a un segmento importante de clientes, grupo entre los cuales se encuentran algunas de las opiniones más favorables y tolerantes sobre el juego (0.c.: 308-311). Es indudable que «el juego» (los juegos de azar) es un fenómeno de fuertes raíces en la cultura de los españoles (y en ascenso a nivel mundial). Pero lo importante es subrayar cómo el juego, en términos generales, en tanto que instrumento indirecto para conseguir rentas excepcionales, es una forma en cierta manera vicaria- de promoción en la escala social, y que ha sido una forma bastante interiorizada por nuestros mayores por las penurias económicas pasadas y/o presentes, pero tambien, de una parte, posiblemente por las limitaciones en la movilidad social de España conocidas por ellos y, de otra, por el alto contenido simbólico que el juego tiene en el imaginario de los mayores. Sabemos positivamente, a través de los referidos estudios (CIS), que hay una cierta afición entre los mayores españoles a las loterías y sorteos (cupón, bonoloto, etc.). En los clubes y hogares de tercera edad se hacen sorteos y rifas, siendo el bingo uno de los juegos que despiertan mayor interés entre los jubilados. I gual mente, los bingos tienen entre sus clientes habituales a personas mayores (viudas frecuentemente) que encuentran en esta actividad (de juego y ocio a la vez) una forma de invertir y de compartir el tiempo entre sus amistades. D e los 3,4 billones de pesetas que España gastó en juegos de azar durante el año 1997, una buena parte habrán sido provenientes de personas mayores (diario $A B C: 7 / 7 / 98$ ). 
Un asunto de interés y en el que escasean los estudios - sobre todo los de corte sociológico- es el referente a los aspectos perversos y/o patológicos del juego en mayores, concretamente los estudios sobre ludopatías entre los mayores, donde es un tema conocido entre especialistas de la psiquiatría y de los servicios sociales el creciente número de mayores que se incorporan a esta patología social (v.g.: Parrondo C arretero, 1994; Tejeiro Sal guero, 1989; Salaberría, 1997; G onzález, 1993), sin que tengamos razones suficientes para afirmar que los mayores sean un grupo de riesgo, lo cierto y verdad es que en general han crecido notablemente los sujetos ludópatas (Becona, 1996, 3454; revista EI M undo: 31/09/98) y que, en consecuencia, también ha crecido el número de jugadores mayores dentro de una patología psicosocial diversa en función del tipo de ludopatía (diario El País: 9/11/98). Como señala una experta: «Es cierto que los jubilados constituyen una población de riesgo donde es previsible que se dé un importante número de jugadores patológicos. Su mucho tiempo libre y ver en el juego un modo de entretenimiento, que además puede mejorar su situación económica (hbitualmente poco boyante), favorecen su participación en el juego de azar» (O choa, Labrador, 1994: 97). 0 tro asunto merece ser mencionado, - si bien tiene una dimensión más de ocio, incluso no monetario- ; nos referimos a la importancia que tiene frecuentemente en el ocio del mayor el juego, sea éste de azar o no. Los tradicionales juegos sociales de cartas (y/o de dominó) se ven a veces incentivados con exiguas cantidades económicas en juego, siempre muy adecuadas al poder adquisitivo de los mayores, teniendo estas cantidades en juego un valor más simbólico y de incentivo que real. M ención aparte merecerían los bingos, que gozan de la simpatía del mayor.

D e otra parte, y según han revelado diferentes estudios de mercado, los sorteos con que se promocionan distintos productos (alimentación fundamental mente) encuentran entre sus clientes habituales a una población femenina y mayor, que con cierta fidelidad envían sus cartas junto a los códigos de barras para participar en todo tipo de sorteos.

\section{La publicidad y los mayores}

Un elemento al que debemos referirnos, para terminar, es la publicidad, donde el mayor raramente es el objeto del mensaje publicitario, y donde tiene ade más un papel claramente secundario y vicario. No vamos a insistir en los hechos sabidos de que la juventud, la alegría, el optimismo, el respeto al medio ambiente y a la naturaleza, el cuerpo esbelto, el cuidado «técnico» y particularizado de cada una de las partes del cuerpo: piel, pelo, cabellos, cara, piel. En suma, la salud unida a la alimentación, al cuerpo como fuente de placer y de protección ante un trabajo duro y competitivo, son y serán el leitmotiv de la publicidad. D esde esta perspectiva, se trata de «combatir» elementos que perturban la estética. Alargar o «disimular»la edad es clave en la publicidad. O cultar-combatir las arrugas, las canas, los kilos, las ojeras, las patas de gallo, la caída del cabello, la caspa, son elementos constantes en la 
publicidad. C on independencia de que hay una magnificación del cuerpo físico dentro de las sociedades contemporáneas de la sociedad de consumo de masas, en general, y tal como señala el profesor Castillo (C astillo Castillo, $1997,35)$ «los seres humanos no solemos contentarnos con el cuerpo que nos ha tocado en suerte [... ] N o hay parte anatómica que haya quedado libre de la intervención humana [... ] Pero todo conforme a una norma social».

D esde esta perspectiva, la presencia del mayor dentro de la publicidad es escasa, tal como hemos señalado. Pero, sin embargo, constituyen un segmento emergente de consumidores, tanto por su creciente número como por la mejora de su poder adquisitivo. El mayor no suele ser objeto directo del espot publicitario (salvo en muy contadas ocasiones en las que sí es consumidor de determinados productos, generalmente de salud u ocio). Pintan más los jóvenes y los niños que los mayores (abuelos). El ser viejo es un accidente en la publicidad, y cuando aparecen mayores raramente lo hacen como tales, sino por los roles que representan (abuela/o, tía, suegra), y en general como contraste con personas más jóvenes con las que se simulan escenarios de contraste de pareceres (Sánchez Vera, Bódalo, 1999: 233-242). En un reciente estudio realizado sobre 25 espots televisivos en los que aparecían sujetos mayores, el perfil tipo era el siguiente: se trataba de una mujer perteneciente a un estatus más bien al to (y con buena imagen), que anunciaba productos alimenticios que no podían ser considerados como específicos para mayores, y que aparecía ejerciendo el rol de abuela a través de los consejos dados dentro de un ambiente familiar y según un model os considerado como tradicional (Sánchez Vera, Bódalo, 1999).

Es verdad que a veces la imagen del mayor, la vemos frecuentemente como rompedora de un modelo tradicional. Así, en algunos esporádicos casos, la figura del mayor en publicidad es utilizada de manera paradójica. Esto es, haciendo funciones impropias de esa edad, como por ejemplo conducir una moto de alta cilindrada por parte de una anciana, o un coche a toda velocidad por una montañosa y sinuosa carretera, para acabar exigiendo una determinada marca de bebida en el primer bar que encuentra. Pero, en general, cuando en los espots publicitarios de televisión aparecen personas mayores, lo suelen hacer en tanto que mediadores o «instrumento» (no como sujeto) en atribución de sus competencias en un determinado tema, aunque sus ideas puedan aparecer como caducas 0 «pasadas de moda». Cuando aparecen mayores, domina el rol femenino - acertado a la sazón al representar mejor la mujer al colectivo de mayores (donde éstas son hegemónicas) - que asesora a su hija (o su nieta) en cuestiones de limpieza-higiene-funciones o roles de la mujer, que en unos casos «suelen estar desfasadas», resaltándose de esta manera el maniqueísmo de la confrontación entre lo «nuevo-moderno» y lo «viejo-tradicional». En otros casos, el mayor o la mayor - sea cual fuere su parentesco: madre-abuela-tía - conoce por profesionalidad y competencia los nuevos productos, esto es: está a la última sobre las características y las ventajas que aporta una determinada «nueva» versión de determinado producto de limpieza, que «sí elimina la grasa, y la salmonella», que une a las carac- 
terísticas de una lejía el cuidado y mimo de la ropa (ahorrando) y a la vez aromatizándola.

La figura del mayor dentro de la publicidad aparece con harta frecuencia con una imagen negativa, bien sea porque el personaje es áspero o repulsivo o por su propia imagen rural y desaliñada. En otros casos, aparecen figuras de personas mayores dentro de un cuadro decorativo de lo que se supone un escenario familiar, este recurso es relativamente frecuente. Raramente los espots publicitarios van directamente dirigidos al anciano, utilizan su figura para dar confianza en unos casos, experiencia en otros, o lo más frecuente para aparecer como anticuados o como «pícaros» y astutos, cuando no «pasados de moda». Sólo en algunos espots se puede decir que tienen como «cliente potencial el anciano». Entre estos anuncios habría que citar: aquéllos que hacen referencia a viajes (económicos), donde es fácil encontrar la figura de personas mayores joviales y dinámicas. Aquéllos que van dirigidos al bolsillo (ahorro), donde la figura del anciano es utilizada con frecuencia. 0 donde se intenta modernizar la mentalidad del anciano en la forma de pago. El tema económico es uno de los más recurrentes motivos en los que el anciano es el sujeto agente al que se dirige el espot, fondos de pensiones, domiciliaciones de pensiones en donde se sortean viajes. La cuota de mercado de este tipo de anuncios es bastante localista y es emitido a través de los canales autonómicos o locales, ya que tienen un componente reducido al ser principalmente las cajas de ahorros los anunciantes. Entre los valores más transmitidos por los espots publicitarios en los que apareen mayores, están el de ahorro, la limpieza, el cuidado y protección de la familia, tanto en términos de salud como de imagen. También los temas de salud son generalmente unos de los que más usan al anciano como sujeto del espot, bien sea como decorados (protectores) o como sujetos. Los temas de alimentación, donde en una sociedad en la que ganan terreno los fast food, - no sólo ya a través de pizzas, hamburguesas, «bocatas», o los platos preparados y preconizados, sean éstos en forma de congelados de todo tipo, enlatados 0 refrigerados- , la figura del anciano (generalmente la anciana), da un toque de cocina tradicional, legitimando y garantizando «técnicamente» que ese plato está hecho con la receta de la abuela. El origen rural y la feminización, son igualmente imágenes presentes en el imaginario colectivo con que la publicidad presenta al anciano.

\section{Bibliografía}

Aguiar, F.; Pérez Yruela, M.; Serran O, R. (1995). «ndicadores sociales de calidad de vida y Tercera Edad». M adrid: C SI C; Instituto de Estudios Sociales Avanzados (IESA). D ocumento de Trabajo, 95-05. M adrid.

AlBerdI, I. (1999). La nueva familia española. M adrid: Taurus.

Alonso, L.E.; Conde, F. (1994). La historia de la sociedad de consumo en España.

$M$ adrid: D ebate. 
Alonso Rivas, J. (1997). Comportamiento del consumidor. Madrid: ESIC.

AN DRÉS O RIZO, F. (1995). Dinámica generacional y sistema de valores de los españo-

les. M adrid: CIS.

ARAN CIBIAS, S. (1997). «EI dinero de la discordia». M adrid: Temas de H oy.

AZo Fra M ÁrQ U EZ, M .J. (1996). Comportamiento de los españoles ante las vacaciones.

$M$ adrid: CIS.

Barea, J. (1988). «Gasto público en pensiones». Papeles de Economía Española, núm. 37, p. 194-205.

BAREA, J.; FERN ÁN DEZ M OREN O, M . (1993). «Evolución demográfica y gasto en protección social en España». Revista del Instituto de Estudios Económicos, 453-471.

BARENYS, M .P. (1993). «Las residencias de ancianos y su significado sociológico». Papers. Revista de Sociología, núm. 40. Bellaterra: U niversitat Autònoma de Barcelona.

BAzo, M .T. (1991). «La familia como elemento fundamental en la salud y bienestar de las personas ancianas». Revista Española de Geriatría y G erontología, núm. 1, p. 47-52.

- (1996). «A portaciones de las personas mayores a la sociedad». REIS, 73. M adrid: CIS.

BLED A, J.M . (1997). Sociedad y Vejez: «Las políticas sociales para la vejez: Percepción, tendencias y líneas de desarrollo». El caso de la Región de Castilla-La M ancha. Cuenca. Universidad de C astilla-La M ancha.

BLEDA, J.M .; CEN TELLES, F.; UÑ A, O . (1998). «ndicadores poblacionales, laborales y económicos de las mujeres viudas en Castilla-La M ancha». VI Congreso Español de sociología. G. 25. A Coruña.

C ABRÉ, A. (1993). «Algunas consideraciones sobre el envejecimiento demográfico en España y su evolución futura». En SÁn Ch EZ Vera, P. (ed.). Sociedad y Población Anciana. M urcia: Servicio de Publicaciones de la Universidad de M urcia.

Cano LozAno, S. (1990). La vejez: integración y exilio. Estudio sociológico en el municipio de Gijón. Gijón: Ayuntamiento de Gijón.

CÁrceles Breis, G. (1996). «La Polémica sobre las prestaciones sociales de vejez: demografía y economía política versus sociología de la ancianidad». REIS, núm. 73, p. 204. M adrid: CIS.

CASAD O, D . (1995). Sobre la pobreza en España. 1965-1994. M adrid: CEBS.

CASt ILlo C ASTILLO, J. (1987). Sociedad de consumo a la española. M adrid: Eudema.

- (1997). «El cuerpo recreado: La construcción social de los atributos corporales». Revista de Sociología (Revista de pensamientos social), núm. 2. La Coruña. Universidad de La C oruña.

CEES (1995) España 1994. «Una interpretación de la realidad social». Centro de Estudios del Cambio Social. M adrid: Fundación Encuentro.

CIRES (1992). La realidad social en España 1990-1991, p. 643-694. M adrid: CIRES.

- (1994). La realidad social en España 1992-1993, p. 806-872. M adrid: CIRES.

- (1994). La realidad social en España 1993-1994, p. 860-917. M adrid: CIRES.

- (1997). La realidad social en España 1994-1995, p. 491-550, 689-755, 776-1063. M adrid: CIRES.

CIS (1966). Estudio número 1.024.

- (1978). Estudio número 1.144.

- (1993). Estudio número 2.072. 
- (1994). Estudio número 2.079.

- (1995). Estudios números 2.186 y 2.187.

- (1996). Estudios números 2.218, 2.219, 2.222 y 2.224.

- (1997). Estudios números 2.235, 2.245, 2.249, 2.251 у 2.253.

- (1998). Estudios números 2.272 y 2.280.

CRUZ, P.; COBO, R. (1990). Situación social de los viejos en España. M adrid: CIS.

Colino SuEIRAS, J. (1994). La economía irregular en la Región de M urcia. Murcia:

Consejo Económico y Social de la Región de M urcia.

CONDE, F. (1994). «N otas sobre la génesis de la sociedad de consumo en España». Política y Sociedad, núm. 16. M adrid: U niversidad Complutense de M adrid.

CRUZ, P. (1994). Representaciones de la sociedad española 1993-1994. M adrid: CIS. Díaz CaSAn OVA, M. (1989). «Envejecimiento de la población y conflicto entre generaciones». REIS, núm. 45, p. 85-113. M adrid: CIS.

DíEZ N ICOLÁs, J. (1997). «La estructura de los hogares españoles». En PuYoL, R. (ed.). Dinámica de la población española. M adrid: Síntesis.

D RURY, E. (1993). «Los trabajadores más veteranos en la Comunidad Europea. Una situación de discriminación generalizada y escasa concienciación». Revista de Gerontología, vol. 3, núm. 4.

ElisARD O, B. (1996). La ludopatía. M adrid: Aguilar.

FERNÁNDEZ CORDON, J.A. (1997). «Youth residencial independence and autonomy. A comparative study». Journal of Family Issues, 6.

FERn ÁN DEZ ENGUITA, M. (1993). «Redes económicas y desigualdades sociales». REIS, núm. 64, p. 41-79. M adrid: CIS.

- (1997). Las personas mayores en el mercado de trabajo. Madrid: Caja Madrid. Roneo.

- (1998). Economía y sociología. M adrid: CIS.

FOESSA (1976). Estudios sociológicos sobrela situación social en España. M adrid: Euroamericana.

- (1994). V Informe Sociológico sobre la situación social de España, vol. 2. M adrid: Fundación FOESSA.

FUndACIÓn ARgENTARIA (1993). I Simposium sobreigualdad y distribución de la renta y la riqueza. M adrid: Fundación Argentaria.

García SAnZ, B. (1997). Envejecimiento en el mundo rural: problemas y soluciones. M adrid: IN SERSO.

Garrid 0, L. (1993). «La familia estatal». En GarRId o L.; GIL Calvo, E. (ed.). Es trategi as familiares. M adrid: Alianza.

GaviRIA, M . (1996). La séptima potencia. Barcelona: Ediciones B.

GaUR, S. CI. (1975). La situación del anciano en España. CECA, p. 265-371. M adrid. Gobierno de N avarra (1997). Plan Gerontológico de N avarra 1997-2000. Pamplona: D epartamento de Bienestar Social, D eporte y Juventud.

GoNZÁLEZ, A. y otros (1996). «uego patológico: un modelo de estudio epidemiológico en población general». Revista Adicciones, vol. 8, núm. 2. Palma de M allorca: Sociodroga-al cohol.

Gran de Esteban, I. (1993). M arketing estratégico para la Tercera Edad. M adrid: ESIC.

- (1999). «Las actitudes de los consumidores mayores ante la compra y sus consecuencias sobre la gestión de marketing». Estudios sobre consumo, núm. 51. M adrid: M inisterio de Sanidad y Consumo. 
Guilem ARD, A.M . (1990). Analyse Comparée des Politiques de la Viellesse en Europe. $M$ adrid: Universidad Autónoma de $M$ adrid. Instituto de las N uevas Tecnologías. H ERCE, J. A. (1998) «La reforma de las pensiones en España». En Alvard o PÉrez, E. (coord.). Retos del Estado del bienestar en España, p. 253-270. M adrid: Tecnos. H ernnández Pedreño, M. (1999). La vejez como experiencia vital. Análisis sociológico de las distintas realidades de la vejez. El caso de la Regi ón de M urcia. Tesis doctoral. Roneo.

H errera, C.; D uran, M.A. (1995). «Las demandas de trabajo no monetarizado

(DETRAN M E) de los ancianos». Revista Política y Sociedad, núm. 19. M adrid. I GLESIAS DE U SSEL, J. (1998). La familia y el cambio político en España. M adrid: Tecnos. IN SERSO (1995). Las personas mayores en España. Perfiles. Reciprocidad. M adrid: $M$ inisterio de Asuntos Sociales.

J OH N SON, N . (1990). El Estado del Bienestar en transición. M adrid: M inisterio de Trabajo y Seguridad Social.

JUSTEL, M . (1983). Los viejos y la política. M adrid: CIS.

Kaufman, A. (1997). Trabajando con mayores. M adrid: CIS.

Ló Pez Alarcón, M.; N AVARRo Vals, R. (1999). Curso de derecho matrimonial canónico. M adrid: Tecnos.

Ló PEZ PINTOR, R. (1987). «La crisis económica y los efectos sobre la familia». En VV.AA. Estudio sobre la familia española. M adrid: M inisterio de Trabajo y Seguridad Social.

M IGUEL, A. DE (1994). La sociedad española 1992-93. M adrid: Alianza.

- (1995). La sociedad española 1993-94. Alianza. M adrid.

- (1995). La sociedad española 1994-95. M adrid: Complutense.

- (1995). La sociedad española 1995-96. M adrid: C omplutense.

- (1995). La sociedad española 1996-97. M adrid: Complutense.

MIGUEL, A. DE; EsCUIN, M. (1997). ABC de la opinión española. M adrid: Espasa. M INISTERIO DE O BRAS PúBLICAS (1991). Encuesta sobre la vivienda familiar en Espa-

ña. M adrid.

M In ISTERIO de SAn ID Ad y Com sum o (1993). Encuesta N acional de Salud. M adrid. M ONCADA, A. (1998). Años dorados. M adrid: Ediciones Libertarias.

M ORAGAS, R. (1981). «Bienestar social del anciano». En IN SERSO . Análisis de la situación del anciano. M adrid.

- (1991). Gerontología Social (envejecimiento y calidad de vida). Barcelona: H erder. N avarro, M. (1987). «Producción y Consumo». En G arm En Dia J.A.; N avarro M.;

ParRa Luna F. (ed.). Sociología Industrial y de la empresa. M adrid: Aguilar.

- (1992). «Apuntes para una teoría de la cultura económica». En M OYA C.; PÉrezAgote, A.; Salcedo, J.; Tezanos, J.F. (ed.). Escritos de Teoría Sociológica. $M$ adrid: CIS.

N OYA, J.; Vallejo, J. (1995). Las actitudes ante la desigualdad social en España. $M$ adrid: CIS.

O CH OA E; LABRAD OR, F.J. (1994). El juego patológico. Barcelona: Plaza y Janés. O RTI, A. (1994). «La estrategia de la oferta en la sociedad neocapitalista de consumo: Génesis y praxis de la investigación motivacional de la demanda». Revista Política y Sociedad, núm. 16. M adrid: Universidad C omplutense de M adrid.

Paniagua, A. (1993). «C onsideraciones sobre el concepto de pobreza aplicado a los ancianos». Revista Epañola de Geriatría y gerontología, núm. 28, 1, p. 12-17. M adrid. 
- (1997). «Agricultores jóvenes y comunidades rurales de ancianos: Un análisis municipal en Castilla-León». Estudios Regionales, núm. 49, p. 87-112. M adrid.

Parron d o Carretero, M.J. (1994). «Ludopatías. Casos prácticos». D ocumentos de

Trabajo Social, núm. 3. M álaga: CO Diplomados en Trabajo Social de Málaga. PÉNE, D . (1999). La civilización de los jubilados. M adrid: Ediciones Encuentro.

PÉrez D íAZ, J. (1996). La situación social de la vejez en España a partir de una perspectiva demográfica. Barcelona: Fundación Caja de M adrid. SG Editores.

- (1996). España puesta a prueba, 1976-1996. M adrid: Alianza.

Pérez O RTIZ, L. (1998). Lasnecesidades de las personas mayores. M adrid: IN SERSO. M inisterio de Trabajo y Asuntos sociales.

Pérez-Agote, A. (1978). «H acia un estatuto teórico del consumo: Jean Baudrillad o la abstracción lógica de la forma». En J IM Én Ez BLAN CO, J.; M OYA, C. (ed.). Teoría Sociológica Contemporánea. M adrid: Tecnos.

Pinto Prades, J.L. (1993) «El uso del análisis coste-beneficio en la atención a los ancianos». En SÁn CHez Vera, P. (ed.). Sociedad y Población Anciana. M urica: Servicio de Publicaciones de la U niversidad de M urcia.

Preston, S. (1984). «C hildren and the elderly in the U.S». Scientific American, núm. 251 (6), p. 36-41.

REIS (1989). Datos de 0 pinión. Separata núm. 45. M adrid: CIS.

RIVAS, D .M.; VARA, M .J. (1989). «L as unidades domésticas como amortiguamiento de la crisis económica». En VV.AA., M ujeres y hombres en la formación del pensamiento occidental, vol. 1, p. 447-453. M adrid: U niversidad Autónoma de M adrid. Rodríguez, J.A. (1991). El cuidado familiar de los ancianos en España. Barcelona: U niversitat de Barcelona. Roneo.

- (1994). Envejecimiento y familia. M adrid: CIS.

Rodríguez Cabrero, G . (1989). «O rígenes y evolución del Estado de bienestar español en su perspectiva histórica». Política y Sociedad, núm. 2, p. 79-87. M adrid.

- (1994). «La política social en España 1980-92». En JUÁREZ, M . (ed.). V Informe Sociológico sobre la Situación Social de España. M adrid: Fundación FO ESSA, p. 1443-1494.

RUESCA, S.M . (1997). Los españoles ante la economía sumergida. M adrid: CIS.

RUIZ DE M AYA, S. (1994). Los grupos de decisión en marketing. Análisis de la familia como unidad de decisión y consumo. M urcia: Servicio de Publicaciones de la Universidad de Murcia.

Sáez M ÉndeZ, H. (1997). Calidad de vida de las personas mayores en Andalucía. Sevilla: Instituto Andaluz de Servicios Sociales. Junta de Andalucía.

SALABARRIA, K. y otros (1997). «El juego patológico: un problema social». Zerbitzuan, núm. 33. Vitoria: Gobierno Vasco.

SALVAD OR, C. (1997). «La protección de la mujer en la vejez: La pensión de viudedad». Información comercial Española, núm. 760. M adrid.

SÁn CH Ez Vera, P. (1993a). «Tercera y Cuarta Edad en España desde la perspectiva de los hogares». REIS, núm. 73. M adrid: CIS.

- (1993b). «Bases y fundamentos para una aproximación sociológica a la vejez». Papers. Revista de Sociología, núm. 40, p. 99-120. Barcelona: U niversitat Autònoma de Barcelona.

- (1998). «Problemática Social de la ancianidad». Jornadas sobre Vejez y Sociedad. Abril de 1988. Albacete: Roneo. 
Sánchez Vera, P.; Bódalo, E. (1999). «La imagen del mayor en los espots publicitarios de televisión». Revista de Gerontología, núm. 4, vol. 9, p. 233-242

- (1999). «Actitudes políticas de los mayores en España». Revista Española de G eriatría y Gerontología, vol. 34 (original aceptado).

Sánchez Vera, P.; Sánchez Galindo, F. (1995). «M ortalidad en accidentes de tráfico de las personas mayores en España». Revista de Gerontología, vol. 5, núm. 2, p. 96-101. Barcelona: SG .

SARA, N . (1993). «El filón de la Tercera Edad». Actualidad Económica, núm. 1815, abril.

SECOT (1995). Las actividades económicas de las personas mayores. M adrid: Seniors Españoles para la Cooperación Técnica.

SEgURA, J. (1988). «Algunos problemas de la protección social. El caso de las pensiones». Papeles de Economía Española, núm. 6, p. 186-193.

Sem Pere N avarro, A. (1993). «Situación jurídica de los trabajadores de edad avanzada». En SÁn chez Vera, P. (ed.). Sociedad y Población Anciana. M urcia: Servicio de Publicaciones de la U niversidad de M urcia, p. 193-212.

SCH ULZ, J.H . (1973). «T he economics of aging». En G RAN D ALL, R.G., (ed.). Gerontology: A behavioral science approach. N ueva York: N ewbery Award Records.

So LÉ, C. (1993). «El enfoque económico en sociología». Revista Internacional de Soci ología. Tercera época, núm. 6, sep-dic. Córdoba: CSIC, p 115-169.

Tejeiro SAlguero, R. (1998). «El juego de azar en Algeciras (España): prevalencia y características sociodemográficas». Revista Española de D rogodependencias, vol. 23, núm. 1. Valencia: Asociación Científica D roga-Alcohol.

TO RRES Ló PEZ, J. (1996). Pensiones públicas: ¿Y mañana qué? Barcelona: Ariel.

VV.AA. (1994) «U tilización del etiquetado de productos de consumo para la Tercera Edad». En Estudios sobre Consumo. M adrid: M inisterio de Sanidad y Consumo, núm. 29.

VV.AA. (1996). Pensiones y prestaciones por desempleo. M adrid: Fundación BBV. VINER, J. (1969). Comercio internacional y desarrollo económico. M adrid: Tecnos. 